\title{
Implication of fault interaction to seismic hazard assessment in Sichuan-Yunnan provinces of southeastern China*
}

\author{
Gkarlaouni $\mathrm{Ch}^{1), \uparrow}$ Papadimitriou E E $\mathrm{E}^{1)}$ Karakostas $\mathrm{V} \mathrm{G}^{1)}$ WEN Xue-ze ${ }^{2)}$ (闻学泽) \\ JIN Xue-shen ${ }^{3)}$ (金学申) Kilias A ${ }^{4)}$ PAN Hua $^{5)}$ (潘 华) YANG Jia-liang ${ }^{3)}$ (杨家亮) \\ 1) Department of Geophysics, Aristotle University of Thessaloniki, GR54124 Thessaloniki, Greece \\ 2) Earthquake Administration of Sichuan Province, Chengdu 610041, China \\ 3) Earthquake Administration of Hebei Province, Shijiazhuang 050021, China \\ 4) Department of Geology, Aristotle University of Thessaloniki, GR54124 Thessaloniki, Greece \\ 5) Institute of Geophysics, China Earthquake Administration, Beijing 100081, China
}

\begin{abstract}
Coulomb stress changes associated with the strong earthquakes that occurred since 1904 in Sichuan and Yunnan provinces of China are investigated. The study area comprises the most active seismic fault zones in the Chinese mainland and suffers from both strong and frequent events. The tectonic regime of this rhombic-shaped area is affected by the eastern extrusion of the Tibetan highland due to the collision of Eurasian Plate against the Indian lithospheric block along the Himalayan convergent zone. This movement is accommodated on major strike-slip intraplate fault zones that strike in an E-W direction. The gradual $90^{\circ}$ clockwise rotation of the faults in the study area contributes to the complexity of the stress field. The seismic hazard assessment in this region is attempted by calculating the change of the Coulomb Failure Function $(\triangle C F F)$ arising from both the coseismic slip of strong events $\left(M_{\mathrm{S}} \geq 6.5\right)$ and the stress built-up by continuous tectonic loading on major regional faults. At every step of the stress evolutionary model an examination of possible triggering of each next strong event is made and the model finally puts in evidence the fault segments that apt to fail in an impending strong event, thus providing future seismic hazard evaluation.
\end{abstract}

Key words: strong earthquakes; fault segmentation; Coulomb stress changes; seismic hazard assessment CLC number: P315.2 Document code: A

\section{Introduction}

Strong seismicity in China and adjacent regions is distributed over specific zones that configure rigid lithospheric subplates often bounded by active faults. Sichuan and Yunnan provinces correspond to a so-called rhombic shaped subplate that experiences the strongest intraplate seismicity in the territory of China. During the 20th century, 35 devastating earthquakes with magnitude $M_{\mathrm{S}} \geq 6.5$ occurred nearby densely populated areas causing a majority of casualties and deaths.

\footnotetext{
* Received 2007-04-25; accepted in revised form 2008-01-16.

Foundation item: The project of bilateral cooperation between Greece and China funded by the General Secretariat of Research \& Technology of Greece (EPAN-M.4.3.6.1/13520) and the Scientific and Technical support project of China (2006BAC13B01).

Contribution No. 699, Department of Geophysics, Aristotle University of Thessaloniki, Greece.

* Author for correspondence: hara.gkarlaouni@gmail.com
} 
Smaller earthquakes are also abundant and are characterized of more dispersing epicentres in the whole southeastern China. This is evidenced in Figure 1 where the seismicity for the period of 1970 2004 is mapped. The study area is treated as an individual microplate that defines the eastern margin of the Tibetan Plateau. During the last 10 Ma post collision extensional stress dominates behind the thrust boundary causing the extrusion of the Plateau main body to the east along east-west rupture zones (Armijo et al, 1986; Molnar and Tapponier, 1977), which have been reactivated as strike slip fault zones since Late Cenozoic time (Wang, 1996).

Sichuan and Yunnan region exhibits a complicated tectonic regime that consists of various rupture zones and different faulting types with strike slip prevailing, which is consistent with the regional stress field and geological background. The study area is being extruded to the southeast, driven in response to the Tibetan Plateau. This motion is combined with a clockwise rotation accomplished around a fixed pole at the eastern edge of the Himalayan syntax according to geologic, tectonic, and geodetic data (Holt et al, 1991; Peltzer and Saucier, 1996). The east margin of the subplate is constrained by the Garzê, Xianshuihe, Anninghe-Zemuhe and Xiaojiang strike slip fault systems, where left lateral displacement dominates. The west boundary is occupied by Jinshajiang and Zhongdian dextral strike slip faults that extend to the south and meet the Red River fault, which is connected with the extrusion of Indonesia to southeast. In the interior of the subplate, normal faults are found with a north-south strike. The tectonic regime of the area is complicated since faults are segmented and also form rotating conjugate fault systems. Strong earthquakes on these faults have been reported both in historic time and instrumental period. In the present study, adjacent faults to the south and the north of Sichuan-Yunnan block are included such as the Wanding, Nanting, Lancang faults to the south and the north Longmenshan thrust and Minjiang fault at the boundary of Sichuan-Qinghai crustal block to the north.

The fact that Sichuan and Yunnan provinces are densely populated and industrially developed urges the necessity for investigating the occurrence pattern of the region's stronger events through a stress evolutionary model and also identifying the structures that are apt to produce a potential strong seismic event in the future. The characteristic of the tectonic setting is that various long strike slip, normal and some thrust faults exist within the same area, interacting with each other. Such interaction of strong earthquakes has been proved by previous investigation concerning the Xianshuihe fault zone (Papadimitriou et al, 2004) and the stress evolution for the northeast Tibetan Plateau from 1920 till present for a viscoelastic model (WAN et al, 2007). Stress transfer seems not only to be restricted in a single however segmented fault but also expands over the adjacent faults or conjugate zones, which often bring them toward rupture. The tectonic complexity reveals a real challenge for our investigation, since the interaction is sought among different faulting types. The purpose of this study is to search for the pattern of stress transfer among various faults and reveal the current stress field that resulted from both the coseismic slip of strong earthquakes and the long term tectonic loading on the major faults zones.

\section{Methodology}

In this study, we apply the stress evolutionary model acquired from Deng and Sykes (1997), who performed a similar investigation for southern California. According to this methodology, the Earth is approximated as an elastic single-layer crust over a homogeneous ductile half space. Stress in the crust is described by a tensor, which varies in time and space and is transmitted elastically due to the accommodated tectonic loading. This long-term process is resulted from relative 
plate motion and from coseismic dislocations evolving in the time interval between strong earthquakes. In order to estimate the stress accumulation in interseismic period around a fault zone, the term of the "virtual dislocation" has been introduced. This concept is based on elastic rebound theory, according to which the stress released in an earthquake existed as pre-stress prior to the event. Hence, the accumulated stress can be determined by supposing that the fault could slip backwards powered by the energy that generates earthquakes. This procedure produces an effective approach to the tectonic loading. The suggested model refers to a planar orthogonal fault surface, $\Sigma$, with finite dimensions, embedded in an elastic half space (Okada, 1992). Displacement, $u$, across a surface, $\Sigma$, of a fault, according to Steketee (1958), is determined from the following equation:

$$
u_{k}=\frac{U_{i}}{8 \pi \mu} \iint_{\Sigma} w_{i j}^{k} v_{j} \mathrm{~d} \Sigma
$$

where $\mu$ is the shear modulus, $v_{j}$ are the direction cosines of the normal to the surface, $U_{i}$ is the $i$ th component of $\boldsymbol{U}$ and $w_{i j}^{k}$ are the six sets of Green's functions. The computation of the elastic stress, $s_{i j}$, derives from strain, $e_{i j}$, using Hooke's law, for an isotropic medium

$$
s_{i j}=\frac{2 \mu \nu}{1-2 v} \delta_{i j} e_{k k}+2 \mu e_{i j}
$$

where $\mu$ is the shear modulus, $v$ is the Poisson's ratio and $\delta_{i j}$ is the Kronecker delta.

Earth in this model is treated as an elastic structure, where postseismic deformation is considered negligible. However, since this time dependent effect is hard to estimate, it is suggested (Jaumé, 1994) that the effect reinforces stress change in the future. According to Nur and Mavko (1974) the relaxation on strike slip faults that govern the study area rarely occurs, because they fail to break to sufficient depth in order to allow measurable postseismic deformation.

According to Scholz (2002) the Coulomb fracture criterion examines the conditions under which failure occurs on brittle rocks. According to this criterion, earthquakes occur along a plane when Coulomb stress exceeds the strength of the rock. Changes in Coulomb failure function $(\triangle C F F)$ depends on the change in shear stress, $\Delta \tau$, on the failure plane and on normal stress, $\Delta \sigma$, and is given by the following equation:

$$
\Delta C F F=\Delta \tau+\mu^{\prime} \Delta \sigma
$$

Here, $\mu^{\prime}$ corresponds to the apparent coefficient of friction, which depends on the coefficient of friction $\mu$ and is given by:

$$
\mu^{\prime}=\mu(1-B)
$$

where $B$ is the Skempton's coefficient, and varies between 0 and 1 . The parameter $\mu^{\prime}$ includes both the effect of pore fluid and material property of the fault zone. The role of $\mu^{\prime}$ corresponding to the change of pore pressure has been widely investigated and is treated as a material constant or a time dependent parameter varying before and after an event. It has been shown that low values of $\mu^{\prime}$ are related to weak fault zones with well-developed gouge often saturated with fluids (Stein, 1999). According to Parsons et al (1999), the apparent coefficient of friction is low for long fault zones $\left(\mu^{\prime}<0.2\right)$ whereas it is high for small ones $\left(\mu^{\prime}>0.8\right)$. Nalbant et al (2002) as well as Toda et al (1998) chose $\mu^{\prime}=0.4$ for their calculations. Reseanberg and Simpson (1992) used $\mu^{\prime}=0.2$ for Loma Prieta earthquake and King et al (1994) suggested that even if $\mu^{\prime}$ varies essentially it 


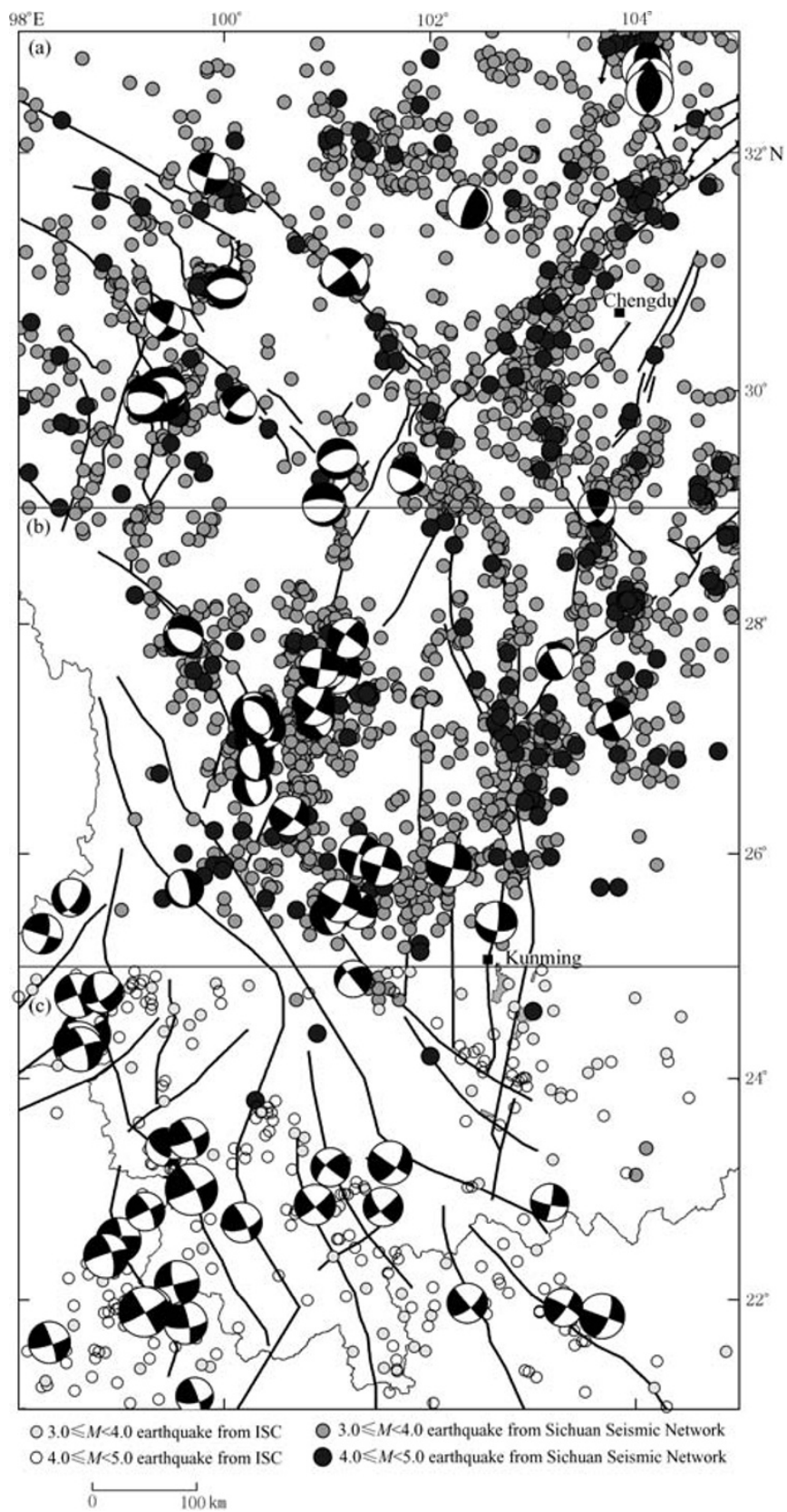

Figure 1 Seismicity in Sichuan-Yunnan provinces from 1970 to 2004

Strong earthquakes mainly distribute along active fault. It is evident that strike slip faults dominate in the whole area. Horizontal lines indicate the division between the northern (a), central (b) and southern sub-region (c)

doesn't alter the stress distribution in adjacent area of the seismic source.

Earthquakes occur due to slip along active fault surfaces approximated as rectangles dipping within the brittle layer of the Earth's crust. Fault planes are adequately described with the geometrical parameters such as the fault length, width, strike and dip. In the absence of geological data or any aftershock information, the geometrical parameters are computed using scaling laws or in- 
ferred by later earthquakes generated by the same fault zone. Papazachos et al (2004) collected worldwide data and suggested scaling laws relating the moment magnitude $(M)$ with fault length, $L(\mathrm{~km})$, and slip, $u(\mathrm{~m})$, for different seismotectonic environments. These laws are used for the model constraints of this study if no other relevant information is available. The equations used for length and coseismic slip for strike slip faults are:

$$
\begin{aligned}
& \lg L=0.59 M-2.30 \\
& \lg u=0.68 M-2.59
\end{aligned}
$$

The corresponding equations for dip slip faults are:

$$
\begin{aligned}
& \lg L=0.50 M-1.86 \\
& \lg u=0.72 M-2.82
\end{aligned}
$$

In addition to the fault geometrical properties the awareness of the fault plane solution regarding the strike, $\xi$, the dip, $\delta$, and the rake, $\lambda$, are essential because the variation of these parameters affects the pattern of the resulted stress field (King et al, 1994). The majority of the fault plane solutions are taken from Yang et al (2005), while additional information from CMT catalogue or local studies dealing with seismic sequences is also used. Moment magnitudes for the earthquakes since 1976 are taken from CMT solutions whereas for the earthquakes before 1976 magnitudes are provided from the seismicity catalogue of Engdahl et al (1998), and $M_{\mathrm{S}}$ magnitudes from Yang et al (2005). The optimal nodal plane for each event is assigned based on available field survey information, such as surface ruptures and in the absence of visible tectonic features, the ones consistent with the regional stress field are chosen. Relocated epicentres from Yang et al (2005) are used, with some exceptions that concern the Songpan and Lung Ling seismic sequence (Jones et al, 1984; CMT Catalogue). Focal depths of the strong earthquakes mainly vary between $3 \mathrm{~km}$ and $15 \mathrm{~km}$ within the crust, determining in this way the width of the brittle seismogenic layer. In order to get more detailed results the study area has been divided into three sub-areas, the northern one (northern Sichuan Province), the central sub-area (southern Sichuan and northern Yunnan provinces) and the southern one (southern Yunnan Province and part of its neighbour countries, Myanmar and Vietnam) (Figure 1).

\section{Fault segmentation and long-term slip rate constraint}

The deformation in China is strongly in response to the kinematic process of the Tibetan Plateau. In central China major fault zones exist, such as Altay fault, trending east-west where large displacements of the order of thousands meters have been identified. Fault offsets mainly observed with the help of geologic markers, such as landforms, alluvian fans and hydrographic features give quantified information on the slip rate for each major fault zone that cuts them across. Using slip rates the mean tectonic motion over a long period of time can be quantified. Slip rates of the major faults in the study area are adopted from various researchers who investigated geologic, geodetic and geomorphologic information or velocity field of crustal motion in China (Chen et al, 2000; Holt et al, 2002; Qin et al, 2002). Slip rates for the most important fault zones in the study area along with their names are illustrated in Figure 2. For a more detailed study the area was divided into three sub areas, and the fault zones were further divided into segments based on the difference of fault properties and slip rates. Information on the fault segmentation for the northern, central and southern region is given in Tables 1, 2 and 3, respectively. 


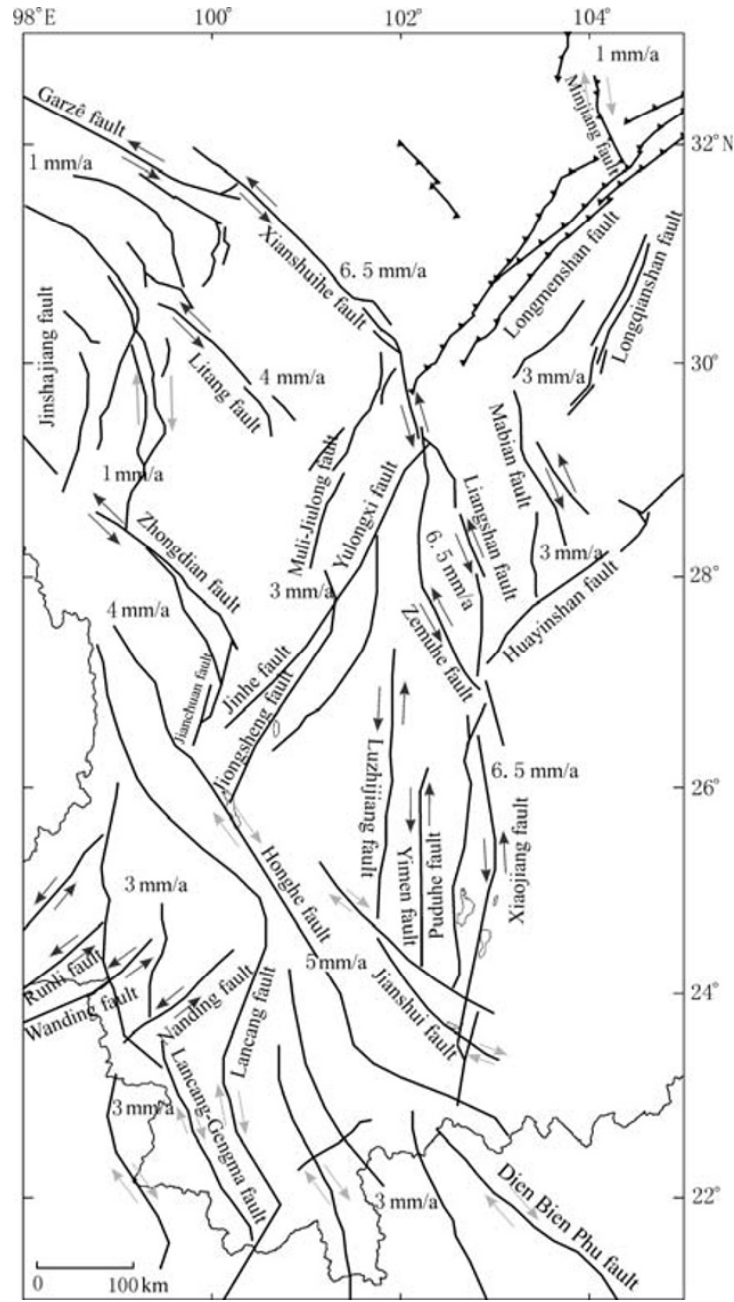

Figure 2 Slip rates on the major faults that are used for determinating tectonic loading

Dark grey colored arrows correspond to left lateral strike slip faults, whereas light dark colored arrows represent right lateral strike slip faults. Rate estimation are based on geodetic seismologic and geologic data
In Figure 3a the 55 fault segments of the northern sub area, the epicentres (denoted by circles) and the fault plane solutions, as lower-hemisphere equal-area projections, of the strong earthquakes included in the evolutionary model are depicted. The Xianshuihe fault is characterized by a relatively high slip rate according to Allen et al (1991), starting with $15 \pm 5 \mathrm{~mm} / \mathrm{a}$ at the northern part and ending up to a reduced value of $5 \mathrm{~mm} / \mathrm{a}$ at the southern edge. The mean slip rate used for the evolutionary model is taken as $6.5 \mathrm{~mm} / \mathrm{a}$ (segments: $S_{30} \sim S_{34}, S_{37} \sim S_{38}$ ) in accordance with Wen et al (2002). The Longmenshan thrust zone is a structure where major shortening around $100 \mathrm{~km}$ occurred due to Tibetan escape tectonics to the east $(\sim 20 \mathrm{~mm} / \mathrm{a})$. The tectonic escarpments formed there are analogous to the Himalayan thrust zone, however recent studies reveal a reduced shortening, probably less than $2 \sim 3 \mathrm{~mm} / \mathrm{a}$. According to Chen et al (2000), the Longmenshan fault zone is characterized by active shortening $<3 \mathrm{~mm} / \mathrm{a}$ while Royden et al (1997) assume that the compression in the whole area is $0 \sim 5 \mathrm{~mm} / \mathrm{a}$. Based on the above, a slip rate equal to $2 \mathrm{~mm} / \mathrm{a}$ is taken (segments $S_{40} \sim S_{45}$ ). In addition to the compression taking place in this part, active strike-slip displacement associated with the Minshan fault $\left(S_{51} \sim S_{53}\right)$ is observed. The slip rate in the latter fault zone is taken equal to $1 \mathrm{~mm} / \mathrm{a}$ following

Kirby et al (2000). The slip rates for the Garzê fault system $\left(S_{1} \sim S_{7}\right)$, the Jinshajiang $\left(S_{10} \sim S_{15}\right.$, $\left.S_{21} \sim S_{24}\right)$ and the Batang $\left(S_{25}\right)$ faults are taken equal to $1 \mathrm{~mm} / \mathrm{a}$ (Zhao et al, 1999). In Longqianshan $\left(S_{46} \sim S_{48}\right)$ and Mabian faults $\left(S_{49} \sim S_{50}\right)$ the attributed slip rate is equal to $3 \mathrm{~mm} / \mathrm{a}$, as referred from Chen et al (2000). Segments $S_{8}$ and $S_{9}$ without particular seismicity exhibit a rate of $1 \mathrm{~mm} / \mathrm{a}$. For the Litang fault $\left(S_{26} \sim S_{29}\right)$ Tang et al (1984) have estimated a rate of $5 \mathrm{~mm} / \mathrm{a}$. Lijiang-Daofu fault that is associated with the 1996 strong earthquake has an average slip rate of $4 \mathrm{~mm} / \mathrm{a}$ (Wang and Burchfiel, 2000).

In Figure $3 b$ the fault segments of the central part of our study area are illustrated, for which long-term slip rate values were assigned based on previous investigations of Wen et al (2000) and 
Table 1 Long-term slip rates on the major fault segments in the northern Sichuan Province

\begin{tabular}{|c|c|c|c|c|c|c|c|}
\hline \multirow{2}{*}{$\begin{array}{c}\text { Segment } \\
\text { No. }\end{array}$} & \multicolumn{2}{|c|}{ Centre } & \multirow{2}{*}{ Length/km } & \multirow{2}{*}{ Depth/km } & \multirow{2}{*}{ Strike/ ${ }^{\circ}$} & \multirow{2}{*}{$\operatorname{Dip} /{ }^{\circ}$} & \multirow{2}{*}{$\begin{array}{l}\text { Slip rate } \\
/ \mathrm{mm} \cdot \mathrm{a}^{-1}\end{array}$} \\
\hline & $\varphi_{\mathrm{N}} /{ }^{\circ}$ & $\lambda_{\mathrm{E}} /{ }^{\circ}$ & & & & & \\
\hline$S_{1}$ & 31.945 & 99.107 & 131 & $0 \sim 15$ & 298 & 65 & 1.0 \\
\hline$S_{2}$ & 31.493 & 99.669 & 52 & $0 \sim 15$ & 300 & 65 & 1.0 \\
\hline$S_{3}$ & 31.625 & 99.000 & 50 & $0 \sim 15$ & 300 & 70 & 1.0 \\
\hline$S_{4}$ & 31.034 & 99.584 & 41 & $0 \sim 15$ & 343 & 70 & 1.0 \\
\hline$S_{5}$ & 31.066 & 100.158 & 20 & $0 \sim 15$ & 190 & 75 & 1.0 \\
\hline$S_{6}$ & 30.974 & 99.997 & 34 & $0 \sim 15$ & 190 & 75 & 1.0 \\
\hline$S_{7}$ & 30.760 & 99.382 & 50 & $0 \sim 15$ & 313 & 75 & 1.0 \\
\hline$S_{8}$ & 31.832 & 102.198 & 30 & $0 \sim 15$ & 137 & 75 & 1.0 \\
\hline$S_{9}$ & 31.486 & 102.489 & 22 & $0 \sim 15$ & 137 & 75 & 1.0 \\
\hline$S_{10}$ & 31.345 & 98.261 & 26 & $0 \neg 15$ & 125 & 75 & 1.0 \\
\hline$S_{11}$ & 30.905 & 98.890 & 56 & $0 \sim 15$ & 140 & 75 & 1.0 \\
\hline$S_{12}$ & 29.864 & 98.975 & 79 & $0 \sim 15$ & 200 & 75 & 1.0 \\
\hline$S_{13}$ & 30.552 & 99.074 & 31 & $0 \sim 15$ & 140 & 75 & 1.0 \\
\hline$S_{14}$ & 29.348 & 98.820 & 16 & $0 \sim 15$ & 182 & 75 & 1.0 \\
\hline$S_{15}$ & 29.915 & 99.221 & 29 & $0 \sim 15$ & 175 & 80 & 1.0 \\
\hline$S_{16}$ & 29.447 & 99.276 & 30 & $0 \sim 15$ & 195 & 80 & 1.0 \\
\hline$S_{17}$ & 29.097 & 99.258 & 13 & $0 \sim 15$ & 180 & 75 & 1.0 \\
\hline$S_{18}$ & 29.964 & 99.357 & 41 & $0 \sim 15$ & 170 & 75 & 1.0 \\
\hline$S_{19}$ & 29.487 & 99.463 & 15 & $0 \sim 15$ & 160 & 75 & 1.0 \\
\hline$S_{20}$ & 29.217 & 99.382 & 22 & $0 \sim 15$ & 337 & 75 & 1.0 \\
\hline$S_{21}$ & 29.987 & 98.641 & 12 & $0 \sim 15$ & 165 & 80 & 1.0 \\
\hline$S_{22}$ & 29.729 & 98.684 & 23 & $0 \sim 15$ & 150 & 75 & 1.0 \\
\hline$S_{23}$ & 30.358 & 98.573 & 16 & $0 \sim 15$ & 183 & 75 & 1.0 \\
\hline$S_{24}$ & 29.311 & 98.596 & 34 & $0 \sim 15$ & 190 & 75 & 1.0 \\
\hline$S_{25}$ & 30.047 & 99.533 & 20 & $0 \sim 15$ & 187 & 84 & 1.0 \\
\hline$S_{26}$ & 30.213 & 99.974 & 66 & $0 \sim 15$ & 138 & 80 & 4.0 \\
\hline$S_{27}$ & 29.880 & 100.569 & 25 & $0 \sim 15$ & 135 & 80 & 4.0 \\
\hline$S_{28}$ & 29.578 & 100.522 & 27 & $0 \sim 15$ & 135 & 80 & 1.0 \\
\hline$S_{29}$ & 29.606 & 100.757 & 19 & $0 \sim 15$ & 135 & 80 & 1.0 \\
\hline$S_{30}$ & 31.295 & 100.734 & 118 & $0 \sim 15$ & 315 & 80 & 6.5 \\
\hline$S_{31}$ & 30.566 & 101.610 & 11 & $0 \sim 15$ & 277 & 87 & 6,5 \\
\hline$S_{32}$ & 30.452 & 101.793 & 15 & $0 \sim 15$ & 315 & 80 & 6.6 \\
\hline$S_{33}$ & 30.305 & 101.789 & 30 & $0 \sim 15$ & 315 & 80 & 6,5 \\
\hline$S_{34}$ & 30.192 & 101.830 & 23 & $0 \sim 15$ & 310 & 85 & 6.5 \\
\hline$S_{35}$ & 29.207 & 101.187 & 29 & $0 \sim 15$ & 221 & 85 & 2.0 \\
\hline$S_{36}$ & 29.509 & 101.595 & 69 & $0 \sim 15$ & 221 & 80 & 2.0 \\
\hline$S_{37}$ & 29.701 & 102.066 & 22 & $0 \sim 15$ & 190 & 80 & 6.5 \\
\hline$S_{38}$ & 29.782 & 101.824 & 50 & $0 \sim 15$ & 160 & 80 & 6.6 \\
\hline$S_{39}$ & 29.201 & 102.241 & 22 & $0 \sim 15$ & 170 & 80 & 6.7 \\
\hline$S_{40}$ & 30.084 & 102.411 & 53 & $0 \sim 15$ & 220 & 50 & 2.0 \\
\hline$S_{41}$ & 31.053 & 103.279 & 90 & $0 \sim 15$ & 211 & 50 & 2.0 \\
\hline$S_{42}$ & 31.770 & 103.888 & 22 & $0 \sim 15$ & 240 & 50 & 2.0 \\
\hline$S_{43}$ & 31.514 & 104.043 & 125 & $0 \sim 15$ & 230 & 50 & 2.0 \\
\hline$S_{44}$ & 30.789 & 103.393 & 122 & $0 \sim 15$ & 215 & 50 & 2.0 \\
\hline$S_{45}$ & 31.754 & 104.557 & 47 & $0 \sim 15$ & 230 & 50 & 2.0 \\
\hline$S_{46}$ & 30.208 & 103.614 & 58 & $0 \sim 15$ & 220 & 80 & 3.0 \\
\hline$S_{47}$ & 30.616 & 104.319 & 66 & $0 \sim 15$ & 200 & 80 & 1.5 \\
\hline$S_{48}$ & 30.518 & 104.374 & 70 & $0 \sim 15$ & 200 & 80 & 1.5 \\
\hline$S_{49}$ & 29.352 & 103.279 & 44 & $0 \sim 15$ & 168 & 80 & 3.0 \\
\hline$S_{50}$ & 29.145 & 103.529 & 16 & $0 \sim 15$ & 170 & 80 & 1.0 \\
\hline$S_{51}$ & 32.791 & 103.723 & 25 & $0 \sim 15$ & 190 & 80 & 1.0 \\
\hline$S_{52}$ & 32.618 & 103.878 & 22 & $0 \sim 15$ & 86 & 80 & 1.0 \\
\hline$S_{53}$ & 32.215 & 104.142 & 50 & $0 \sim 15$ & 170 & 80 & 1.0 \\
\hline$S_{54}$ & 32.335 & 104.701 & 36 & $0 \sim 15$ & 240 & 50 & 1.0 \\
\hline$S_{55}$ & 31.597 & 100.181 & 11 & $0 \sim 15$ & 245 & 45 & 6.5 \\
\hline$S_{56}$ & 32.244 & 103.620 & 41 & $0 \sim 15$ & 10 & 60 & 1.0 \\
\hline
\end{tabular}


Table 2 Long-term slip rates on the major fault segments in the central Sichuan-Yunnan province

\begin{tabular}{|c|c|c|c|c|c|c|c|}
\hline \multirow{2}{*}{$\begin{array}{c}\text { Segment } \\
\text { No. }\end{array}$} & \multicolumn{2}{|c|}{ Center } & \multirow{2}{*}{ Length/km } & \multirow{2}{*}{ Depth/km } & \multirow{2}{*}{ Strike ${ }^{\circ}$} & \multirow{2}{*}{ Dip ${ }^{\circ}$} & \multirow{2}{*}{$\begin{array}{l}\text { Slip rate } \\
/ \mathrm{mm} \cdot \mathrm{a}^{-1}\end{array}$} \\
\hline & $\varphi_{\mathrm{N}} /^{\circ}$ & $\lambda_{\mathrm{E}} /^{\circ}$ & & & & & \\
\hline$S_{1}$ & 28.599 & 99.096 & 13 & $0 \sim 15$ & 3 & 60 & 3.0 \\
\hline$S_{2}$ & 28.853 & 99.189 & 18 & $0 \sim 15$ & 30 & 60 & 3.0 \\
\hline$S_{3}$ & 28.084 & 99.597 & 104 & $0 \sim 15$ & 130 & 70 & 4.2 \\
\hline$S_{4}$ & 27.663 & 99.729 & 86 & $0 \sim 15$ & 150 & 70 & 4.2 \\
\hline$S_{5}$ & 27.069 & 100.125 & 43 & $0 \sim 15$ & 10 & 75 & 4.0 \\
\hline$S_{6}$ & 26.681 & 99.894 & 33 & $0 \sim 15$ & 10 & 75 & 4.0 \\
\hline$S_{7}$ & 26.238 & 99.809 & 168 & $0 \sim 15$ & 330 & 80 & 5.0 \\
\hline$S_{8}$ & 26.708 & 98.954 & 76 & $0 \sim 15$ & 345 & 80 & 5.0 \\
\hline$S_{9}$ & 25.501 & 99.820 & 90 & $0 \sim 15$ & 315 & 80 & 5.0 \\
\hline$S_{10}$ & 25.309 & 98.612 & 33 & $0 \sim 15$ & 223 & 75 & 3.0 \\
\hline$S_{11}$ & 25.510 & 98.898 & 58 & $0 \sim 15$ & 190 & 75 & 3.0 \\
\hline$S_{12}$ & 28.586 & 101.183 & 55 & $0 \sim 15$ & 195 & 75 & 3.0 \\
\hline$S_{13}$ & 28.391 & 101.725 & 81 & $0 \sim 15$ & 210 & 75 & 3.8 \\
\hline$S_{14}$ & 27.119 & 100.764 & 91 & $0 \sim 15$ & 220 & 75 & 3.8 \\
\hline$S_{15}$ & 26.825 & 100.779 & 125 & $0 \sim 15$ & 205 & 80 & 3.0 \\
\hline$S_{16}$ & 26.617 & 100.962 & 37 & $0 \sim 15$ & 220 & 80 & 3.0 \\
\hline$S_{17}$ & 27.131 & 101.476 & 50 & $0 \sim 15$ & 210 & 75 & 3.0 \\
\hline$S_{18}$ & 27.974 & 101.748 & 50 & $0 \sim 15$ & 190 & 75 & 3.0 \\
\hline $\mathrm{S}_{19}$ & 26.133 & 101.917 & 131 & $0 \sim 15$ & 2 & 75 & 2.0 \\
\hline$S_{20}$ & 25.517 & 102.224 & 54 & $0 \sim 15$ & 5 & 75 & 2.0 \\
\hline$S_{21}$ & 26.062 & 102.251 & 13 & $0 \sim 15$ & 13 & 80 & 2.0 \\
\hline$S_{22}$ & 28.375 & 102.195 & 55 & $0 \sim 15$ & 180 & 75 & 6.5 \\
\hline$S_{23}$ & 27.289 & 102.566 & 63 & $0 \sim 15$ & 330 & 75 & 65 \\
\hline$S_{24}$ & 26.688 & 102.273 & 19 & $0 \sim 15$ & 190 & 75 & 6.5 \\
\hline$S_{25}$ & 26.842 & 102.743 & 26 & $0 \sim 15$ & 175 & 84 & 6.5 \\
\hline$S_{26}$ & 26.215 & 102.698 & 19 & $0 \sim 15$ & 180 & 80 & 6.5 \\
\hline$S_{27}$ & 25.530 & 102.692 & 56 & $0 \sim 15$ & 185 & 80 & 6.5 \\
\hline$S_{28}$ & 26.591 & 102.812 & 22 & $0 \sim 15$ & 190 & 80 & 6.5 \\
\hline$S_{29}$ & 25.974 & 102.919 & 58 & $0 \sim 15$ & 175 & 80 & 6.5 \\
\hline$S_{30}$ & 25.253 & 103.003 & 27 & $0 \sim 15$ & 182 & 80 & 5.0 \\
\hline$S_{31}$ & 28.485 & 102.680 & 59 & $0 \sim 15$ & 163 & 87 & 3.0 \\
\hline$S_{32}$ & 27.510 & 102.875 & 54 & $0 \sim 15$ & 182 & 80 & 3.0 \\
\hline$S_{33}$ & 26.717 & 103.003 & 34 & $0 \sim 15$ & 170 & 80 & 3.0 \\
\hline$S_{34}$ & 27.761 & 103.477 & 90 & $0 \sim 15$ & 236 & 85 & 3.0 \\
\hline$S_{35}$ & 28.231 & 103.408 & 45 & $0 \sim 15$ & 182 & 85 & 3.0 \\
\hline$S_{36}$ & 28.407 & 104.534 & 25 & $0 \sim 15$ & 220 & 89 & 3.0 \\
\hline$S_{37}$ & 28.674 & 103.620 & 43 & $0 \sim 15$ & 155 & 80 & 3.0 \\
\hline$S_{38}$ & 28.798 & 103.814 & 27 & $0 \sim 15$ & 140 & 80 & 3.0 \\
\hline
\end{tabular}

YI et al (2004), who estimated a rate of $6 \sim 7 \mathrm{~mm} / \mathrm{a}$. Thus, a slip rate of $6.5 \mathrm{~mm} / \mathrm{a}$ is attributed to Anninghe and Zemuhe faults $\left(S_{22} \sim S_{23}\right)$, as well as in the whole left lateral fault zone $\left(S_{30} \sim S_{34}, S_{38}\right.$, $S_{39}$ ). The Zhongdian (segments $S_{3} \sim S_{5}$ ) and Jianchuan fault zones $\left(S_{6}\right)$ have a rate of $4 \mathrm{~mm} / \mathrm{a}$, taking into account the results of Wang and Burchfiel (2000). In this area, the northern active segment $\left(S_{7}\right)$ of Red River fault is included with a slip rate equal to $5 \mathrm{~mm} /$ a (Leloup et al, 1995). For the Huayinshan $\left(S_{34} \sim S_{38}\right)$, Liangshan $\left(S_{31} \sim S_{32}\right)$ and the Yulongxi $\left(S_{13}\right)$ fault zones that are located in the broader area of Sichuan basin an average slip rate of $3 \mathrm{~mm} / \mathrm{a}$ is assigned, taking into account the GPS measurements of Chen et al (2000). The Yongsheng $\left(S_{15}\right)$ and Muli-Jiulong $\left(S_{12}\right)$ faults are slipping at a rate of $3 \mathrm{~mm} / \mathrm{a}$ in accordance with Qinhe fault $\left(S_{14}\right)$ moving with $3.8 \pm 0.7$ $\mathrm{mm}$ annualy estimated from Xu et al (2003). The same value with Qinhe has been given to the Puduhe, Yimen and Luzhijiang left lateral faults striking north-south, parallel to Xiaojiang fault.

Fault segmentation of the southern part of the study area is presented in Figure 3c. The longest part of the Red River fault is included in this area. Allen et al (1984) estimated a rate varying from 2 to $7 \mathrm{~mm} / \mathrm{a}$ with a total offset of $5.5 \mathrm{~km}$, considering features of surface faulting, fault 
Table 3 Long-term slip rates on the major fault segments in the southern Yunnan Province

\begin{tabular}{|c|c|c|c|c|c|c|c|}
\hline \multirow{2}{*}{$\begin{array}{l}\text { Segment } \\
\text { No. }\end{array}$} & \multicolumn{2}{|c|}{ Center } & \multirow{2}{*}{ Length/km } & \multirow{2}{*}{ Depth/km } & \multirow{2}{*}{ Strike ${ }^{\circ}$} & \multirow{2}{*}{$\mathrm{Dip} /{ }^{\circ}$} & \multirow{2}{*}{$\begin{array}{l}\text { Slip Rate } \\
/ \mathrm{mm} \cdot \mathrm{a}^{-1}\end{array}$} \\
\hline & $\varphi_{\mathrm{N}} /^{\circ}$ & $\lambda_{\mathrm{E}} /^{\circ}$ & & & & & \\
\hline$S_{1}$ & 24.837 & 98.206 & 27 & $0 \sim 15$ & 223 & 70 & 3.0 \\
\hline$S_{2}$ & 24.371 & 98.461 & 58 & $0 \sim 15$ & 229 & 69 & 3.0 \\
\hline$S_{3}$ & 23860 & 98.372 & 43 & $0 \sim 15$ & 242 & 70 & 3.0 \\
\hline$S_{4}$ & 24.258 & 99.093 & 44 & $0 \sim 15$ & 229 & 70 & 3.0 \\
\hline$S_{5}$ & 24.636 & 98.877 & 33 & $0 \sim 15$ & 188 & 75 & 3.0 \\
\hline$S_{6}$ & 23.952 & 98.998 & 43 & $0 \sim 15$ & 178 & 75 & 3.0 \\
\hline$S_{7}$ & 23.418 & 99.294 & 27 & $0 \sim 15$ & 130 & 75 & 3.0 \\
\hline$S_{8}$ & 24.694 & 99.497 & 26 & $0 \sim 15$ & 170 & 75 & 1.0 \\
\hline$S_{9}$ & 24.357 & 99.456 & 25 & $0 \sim 15$ & 200 & 75 & 1.0 \\
\hline$S_{10}$ & 23.967 & 99.348 & 23 & $0 \sim 15$ & 180 & 75 & 1.0 \\
\hline$S_{11}$ & 23.930 & 99.694 & 79 & $0 \sim 15$ & 225 & 75 & 1.0 \\
\hline$S_{12}$ & 22.999 & 98.940 & 23 & $0 \sim 15$ & 12 & 75 & 3.0 \\
\hline$S_{13}$ & 22.599 & 98.954 & 20 & $0 \sim 15$ & 345 & 75 & 3.0 \\
\hline$S_{14}$ & 22.009 & 99.300 & 55 & $0 \sim 15$ & 349 & 75 & 3.0 \\
\hline$S_{15}$ & 21.430 & 99.513 & 13 & $0 \sim 15$ & 24 & 80 & 3.0 \\
\hline$S_{16}$ & 22.529 & 99.866 & 118 & $0 \sim 15$ & 340 & 80 & 3.0 \\
\hline$S_{17}$ & 24.708 & 100.58 & 27 & $0 \sim 15$ & 350 & 75 & 3.0 \\
\hline$S_{18}$ & 23.889 & 100.33 & 65 & $0 \sim 15$ & 20 & 75 & 3.0 \\
\hline$S_{19}$ & 22.996 & 100.17 & 41 & $0 \sim 15$ & 350 & 75 & 3.0 \\
\hline$S_{20}$ & 22.282 & 100.49 & 45 & $0 \sim 15$ & 337 & 75 & 3.0 \\
\hline$S_{21}$ & 21.480 & 100.42 & 59 & $0 \sim 15$ & 30 & 80 & 3.0 \\
\hline$S_{22}$ & 23.316 & 100.71 & 26 & $0 \sim 15$ & 2 & 75 & 3.0 \\
\hline$S_{23}$ & 22.564 & 100.97 & 69 & $0 \sim 15$ & 150 & 75 & 3.0 \\
\hline$S_{24}$ & 21.526 & 101.41 & 29 & $0 \sim 15$ & 167 & 75 & 3.0 \\
\hline$S_{25}$ & 23.772 & 100.89 & 54 & $0 \sim 15$ & 160 & 84 & 3.0 \\
\hline$S_{26}$ & 22.639 & 101.35 & 79 & $0 \sim 15$ & 140 & 80 & 3.0 \\
\hline$S_{27}$ & 22.508 & 101.30 & 47 & $0 \sim 15$ & 50 & 80 & 1.0 \\
\hline$S_{28}$ & 24.496 & 101.01 & 65 & $0 \sim 15$ & 150 & 80 & 5.0 \\
\hline$S_{29}$ & 23.718 & 101.43 & 29 & $0 \sim 15$ & 165 & 80 & 5.0 \\
\hline$S_{30}$ & 23.104 & 102.20 & 86 & $0 \sim 15$ & 124 & 80 & 5.0 \\
\hline$S_{31}$ & 21.904 & 102.46 & 111 & $0 \sim 15$ & 150 & 87 & 3.0 \\
\hline$S_{32}$ & 21.819 & 103.30 & 134 & $0 \sim 15$ & 135 & 80 & 3.0 \\
\hline$S_{33}$ & 23.316 & 102.68 & 51 & $0 \sim 15$ & 195 & 80 & 3.0 \\
\hline$S_{34}$ & 24.133 & 102.04 & 38 & $0 \sim 15$ & 325 & 85 & 3.0 \\
\hline$S_{35}$ & 23.543 & 102.67 & 43 & $0 \sim 15$ & 310 & 85 & 3.0 \\
\hline$S_{36}$ & 24.636 & 101.74 & 52 & $0 \sim 15$ & 144 & 89 & 3.0 \\
\hline$S_{37}$ & 24.040 & 102.51 & 55 & $0 \sim 15$ & 290 & 80 & 3.0 \\
\hline$S_{38}$ & 24.609 & 102.56 & 52 & $0 \sim 15$ & 5 & 80 & 3.0 \\
\hline$S_{39}$ & 24.644 & 102.21 & 40 & $0 \sim 15$ & 5 & 80 & 3.0 \\
\hline$S_{40}$ & 24.241 & 102.76 & 90 & $0 \sim 15$ & 10 & 80 & 3.0 \\
\hline$S_{41}$ & 24.848 & 101.75 & 15 & $0 \sim 15$ & 5 & 80 & 3.0 \\
\hline
\end{tabular}

scarps, stream channel offsets, and younger formations cut by the fault. According to Replumaz et al (2001), slip rate of the Red River fault ranges from 1 to $10 \mathrm{~mm} / \mathrm{a}$ based on the geomorphic disturbances of the drainage network. The hardness in assessing the age of geomorhologic marker offset causes the scattering of the estimated slip rates. Leloup et al (1995) suggested a rate of about $5 \mathrm{~mm} / \mathrm{a}$, taking into account that the left lateral motion ceased around $15 \mathrm{Ma}$ and the fault was reactivated as a dextral one around $15 \mathrm{Ma}$. The fault segments to the south of the Red River fault zone present a slip rate equal to $3 \mathrm{~mm} / \mathrm{a}$. Segment $S_{7}$ as well as segments $S_{28} \sim S_{30}$ slip with a rate of $5 \mathrm{~mm} / \mathrm{a}$. Nanting and Wanding faults $\left(S_{2} \sim S_{4}\right)$ slip with a rate of $3 \mathrm{~mm} / \mathrm{a}$ (Socquet and, Pubellier, 2005). Qujiang and Jianshui faults $\left(S_{36} \sim S_{37}\right.$ and $S_{34}$ ) located to the north of Red River fault exhibit a slip rate of $3 \pm 3 \mathrm{~mm} / \mathrm{a}$ (Leloup et al, 1995). The rest of the zones striking NE-SW and its NW-SE conjugate ones, located to the south of the Red River fault trace $\left(S_{1}, S_{11} \sim S_{15}, S_{17} \sim S_{26}\right.$, 

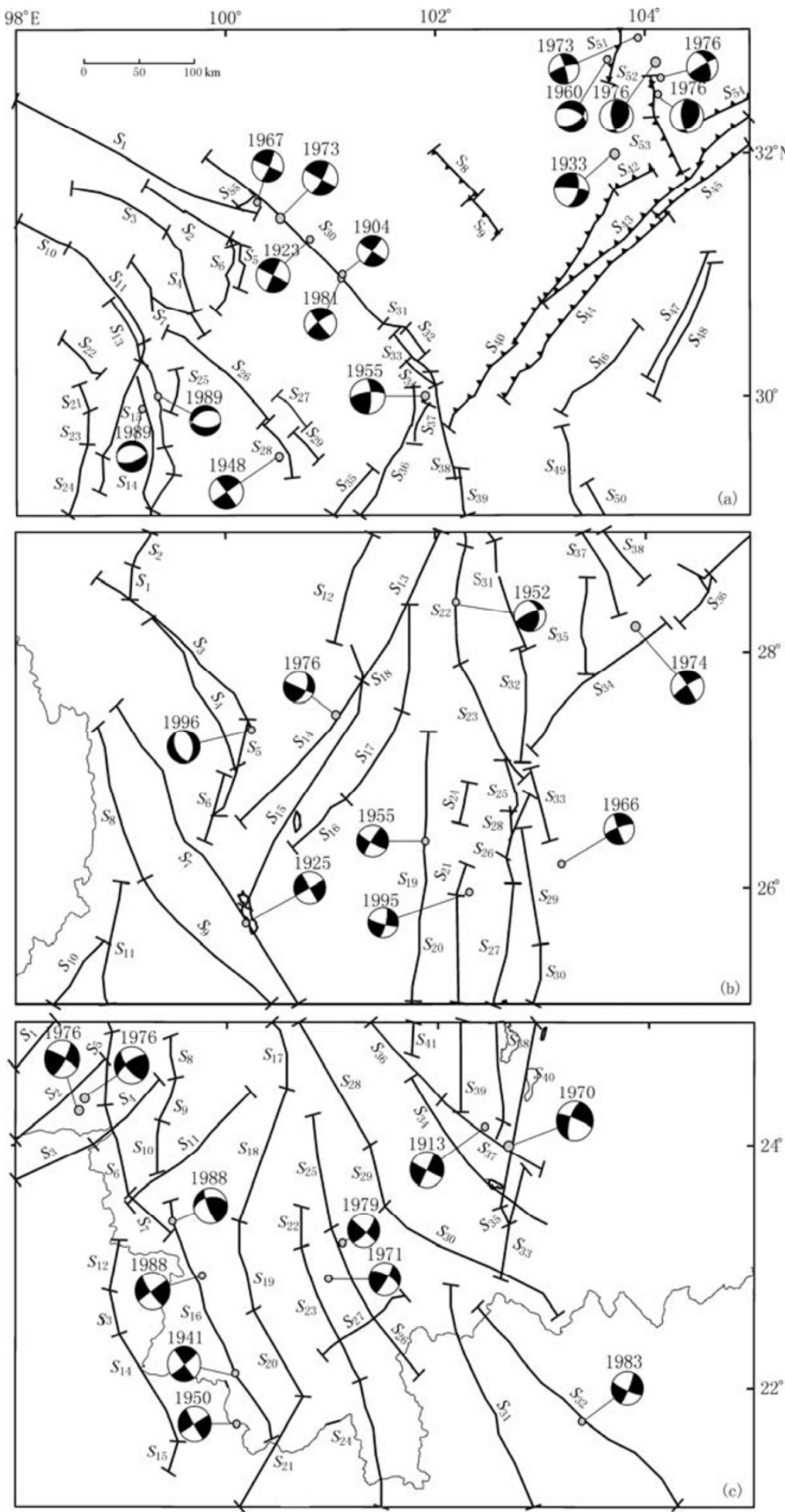

Figure 3 Segmentation of major faults in the study area (a) northern region, (b) central region, (c) southern region 
$\left.S_{31} \sim S_{32}\right)$, including Lancang-Gengma zone $\left(S_{16}\right)$ also slip with an average rate of $3 \mathrm{~mm} / \mathrm{a}$, according to Allen et al (1984) and Socquet and Pubellier (2005).

\section{Stress evolutionary model}

The evolution of stress field before the occurrence of each strong event is computed at a depth of $8 \mathrm{~km}$, chosen to be several kilometers above the locked depth of the seismogenic layer and approximately in the middle of the brittle crust and the resulted pattern is presented as snapshots (Figures 4, 5 and 6). The parameters included in equations (1) and (2) such as the shear modulus and Poisson's ratio are fixed as $33 \mathrm{GPa}$ and 0.25 , respectively. However, alternative values for the apparent coefficient of friction have been testified in order to detect possible variations in the stress pattern. The calculated stress field includes a combination of both coseismic stress change and the effect of the cumulative seismic displacements on major structures measured from a starting event. The dense fault network results in a complicated distribution of stress change over the region. It is considered that before the first strong shock of 1904, 1913 and 1925 for the southern, central and northern region, respectively, $\triangle C F F$ are originally zero. Changes in shear and normal stress of each earthquake are resolved onto the subsequent event's fault plane, as it has been assumed to be in accordance with the orientation of regional stress. Therefore, the stress field before an earthquake is analyzed for the faulting type of the causative fault colored black. The results are exhibited in a schematic manner, with the stress change denoted with a color scale. In the snapshots pure green indicates no significant change in Coulomb stress. Blue regions denote negative change in CFF and infer decreased likelihood of fault rupture, and are called stress shadows (Harris and Simpson, 1993, 1996). Yellow to red regions represent positive $\triangle C F F$ and increased likelihood of fault rupture, so they are called stress bright zones. Shadow zones and bright zones are specific to strike, dip, and rake of the fault whose triggering is inspected.

\subsection{Northern Sichuan region}

The evolutionary stress model for the northern part of the study area is presented in the snapshots of Figure 4. The first strong event occurred in 1904 in Daofu fault segment and its coseismic stress change is shown in Figure 4a. The stress pattern corresponds to a typical strike slip faulting that creates a bright zone at the northern and southern tip of the fault that ruptured, whereas large parts are under a stress shadow. Two increased stress lobes are along the strike of the Xianshuihe fault zone and the other two are perpendicular to them. The Luhuo earthquake in 1923 is favored to be triggered since its epicenter is located in the region with increased Coulomb stress. In Figure 4b the stress accumulation before the 1923 event is displayed. There is strong evidence that the earthquake had been advanced by the 1904 event occurrence since it is obviously located in a bright zone created by the previous event. In Figure $4 \mathrm{c}$ the stress field calculated according to the faulting type of the 1933 Diexi earthquake is shown. The epicenter of this event is quite far from the previous ones to be triggered by them, and the positive $\triangle C F F$ are due solely to the tectonic loading. The stress field just before the 1948 earthquake is shown in Figure 4d, indicating that the associated fault is located inside a bright zone. The 1955 rupture is located in an enhanced stress area (Figure 4e) and is probably triggered by the previous occurrences on the Xianshuihe and Litang faults. The 1960 event is close to a stress shadow zone created by the 1933 Diexi earthquake (Figure 4f). This mismatch may attribute either to errors in epicentral determination or to blind normal fault associated with this event. The 1967 Zhuwo event occurred inside a stress enhanced area attributed to the coseismic stress change of previous events along the Xianhsuihe 

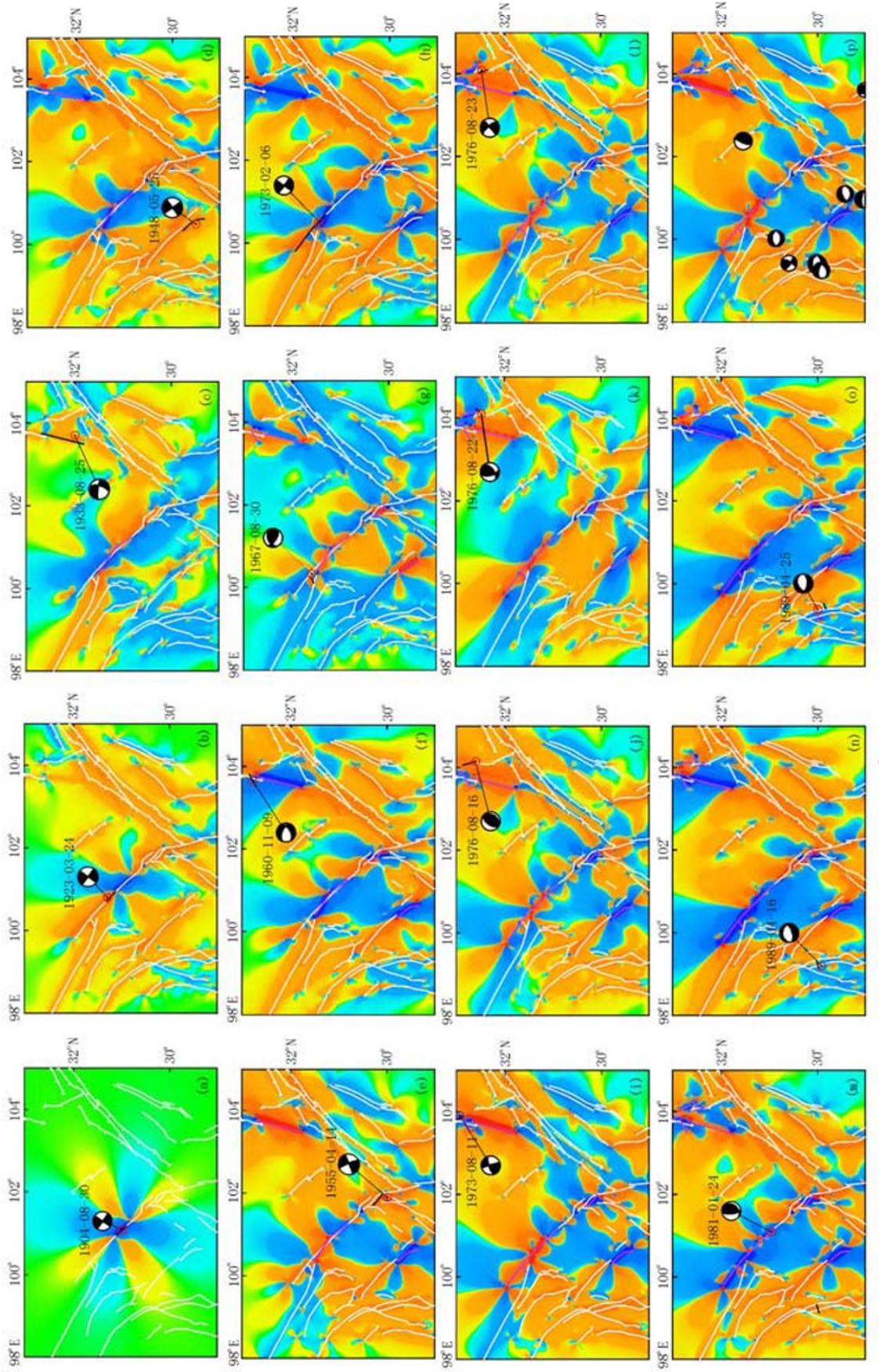

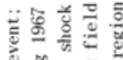

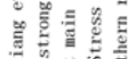

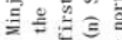

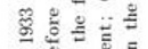

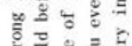

5)

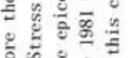

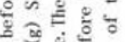

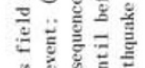

2.8.

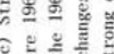

]

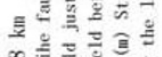

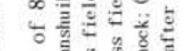

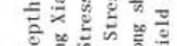

每

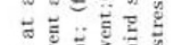

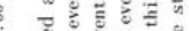

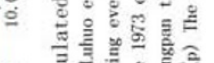

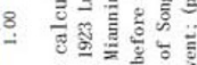

$\circ 8$

(1)

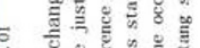

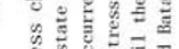

(5)

을

항

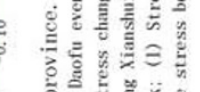

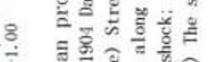

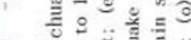

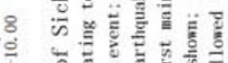

응

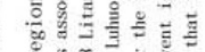

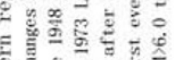

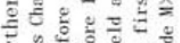

눙

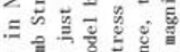

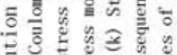

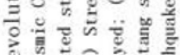

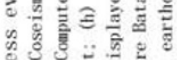

的国

密 
Table 4 Rupture models for earthquakes with $M \geq 6.5$ that occurred in the northern part (northern Sichuan Province) of the study area from 1904 to 1989 and are included in the evolutionary model

\begin{tabular}{|c|c|c|c|c|c|c|c|c|c|c|c|c|c|}
\hline \multirow{2}{*}{$\begin{array}{c}\text { Date } \\
\text { a-mo-d }\end{array}$} & \multirow{2}{*}{ Location } & \multicolumn{2}{|c|}{ Epicenter } & \multicolumn{2}{|c|}{ Magnitude } & \multicolumn{3}{|c|}{ Fault plane solution } & \multirow{2}{*}{$L / \mathrm{km}$} & \multirow{2}{*}{$U / \mathrm{m}$} & \multirow{2}{*}{$S S / \mathrm{m}$} & \multirow{2}{*}{$D S / \mathrm{m}$} & \multirow{2}{*}{ Ref. } \\
\hline & & $\varphi_{\mathrm{N}} /^{\circ}$ & $\lambda_{\mathrm{E}} /^{\circ}$ & $M_{\mathrm{S}}$ & $M_{\mathrm{W}}$ & Strike ${ }^{\circ}$ & Dip/ ${ }^{\circ}$ & Rake $/^{\circ}$ & & & & & \\
\hline 1904-08-30 & Xianshuihe & 31.00 & 101.10 & 6.8 & 6.8 & 322 & 85 & 13 & 50 & 1.08 & +1.05 & -0.23 & 1,2, Eq. 6 \\
\hline 1923-03-23 & Xianshuihe & 31.30 & 100.80 & 7.2 & 7.2 & 116 & 90 & 10 & 60 & 2.36 & +2.30 & 0 & 1, 2, Eq.6 \\
\hline $1933-08-25$ & Minjiang & 32.00 & 103.70 & 7.3 & 7.3 & 14 & 60 & -167 & 102 & 2.36 & -2.29 & +0.53 & 3, Eq. 5-6 \\
\hline $1948-05-25$ & Litang & 29.50 & 100.50 & 7.3 & 7.3 & 315 & 90 & 0 & 60 & 2.36 & +2.35 & -0.04 & 4, 2, Eq. 6 \\
\hline 1955-04-14 & Xianshuihe & 30.00 & 101.90 & 7.5 & 7.5 & 337 & 81 & -3 & 35 & 3.23 & +3.23 & -0.10 & 1,4, Eq. 6 \\
\hline 1960-11-09 & Minjiang & 32.78 & 103.66 & 6.5 & & 60 & 50 & -130 & 34 & 0.68 & -0.44 & +0.52 & 3,5, Eq.7-8 \\
\hline 1967-08-30 & Xianshuihe & 31.61 & 100.33 & 6.8 & 6.1 & 245 & 45 & 42 & 20 & 1.48 & +0.59 & -0.53 & 6, Eq. 7 \\
\hline 1973-02-06 & Xianshuihe & 31.48 & 100.53 & 7.6 & 7.4 & 125 & 87 & 0 & 116 & 2.77 & +2.77 & 0 & 1,6 , Eq.7-8 \\
\hline 1973-08-11 & Minjiang & 32.93 & 103.90 & 6.5 & 6.1 & 343 & 85 & 15 & 20 & 0.36 & +0.34 & -0.09 & 3, Eq. 8 \\
\hline 1976-08-11 & Songpan & 32.61 & 104.13 & 7.2 & 6.7 & 165 & 63 & 40 & 30 & 1.1 & +0.84 & -0.7 & 7 \\
\hline 1976-08-21 & Songpan & 32.60 & 104.40 & 6.7 & 6.3 & 215 & 30 & 90 & 12 & 1.2 & 0 & -1.2 & 7 \\
\hline $1976-08-23$ & Songpan & 32.50 & 104.30 & 7.2 & 6.4 & 165 & 65 & 40 & 22 & 1.1 & +0.84 & -0.7 & 7 \\
\hline 1981-01-23 & Xianshuihe & 30.98 & 101.10 & 6.9 & 6.5 & 319 & 73 & -4 & 47 & 0.56 & +0.56 & +0.03 & 2, 8, Eq.6 \\
\hline 1989-04-16 & Batang & 29.92 & 99.20 & 6.4 & 6.5 & 74 & 62 & -99 & 22 & 0.54 & -0.08 & +0.53 & $3,9,10$, Eq. 7 \\
\hline 1989-04-25 & Batang & 30.00 & 99.370 & 6.7 & 6.1 & 245 & 40 & -114 & 15.5 & 0.32 & -0.13 & +0.3 & 3,10, Eq. 7 \\
\hline
\end{tabular}

fault zone and the tectonic loading (Figure 4g). In this case triggering is noticed in a secondary structure almost perpendicular to the previously ruptured causative faults.

The Luhuo fault segment that failed in 1973 was well inside a bright zone (Figure 4h). The location of the 1973 Minjiang earthquake is not predicted by the evolutionary model, since it is located in a stress shadow (Figure 4i). Nevertheless its coseismic slip contributes to the increase of positive stress change in the Songpan region that suffered few years later from a triplet of strong events in 1976 across the Huya fault. This is a rather seldom and complex phenomenon which is characterized of the subsequent strong earthquakes that occur close in time and space. They are attributed to en enchelon structure with two strands separated by an additional right stepping offset and the strong influence among the three main shocks is proved. In Figure $4 \mathrm{j}$ the calculated stress field before the first 1976 Songpan earthquake is shown. It is suggested that the Huya fault is advanced toward failure and triggered by the increased stress change induced by the 1933 Diexi and 1973 Minjiang main events, since the whole area around the fault is located in a bright zone. The stress transfer from the first rupture brought the second en enchelon segment closer to failure, since the positive stress change is provoked mainly by the first 1976 event (Figure 4k). Thirty hours after the second mainshock the last one occurred, south of the second aftershock zone (Figure 4l) in an enhanced stress zone reinforced by the previous strong events.

The most recent significant earthquake along Xianshuihe fault zone occurred in 1981 and is associated with the Daofu fault segment that ruptured for a second time (the first was in 1904) in the 20th century. It is noticed that the stress change is not enhanced enough so as to interpret the occurrence of Daofu earthquake (Figure $4 \mathrm{~m}$ ). Both the epicentre of the first Batang earthquake and the associated fault, are located in a stress shadow zone (Figure 4n). A possible explanation is the lack of geologic knowledge and the tectonic complexity of the region as well as the incompatibility between the mapped faults and the fault plane solutions. The remarkable characteristic is that the events are produced in a region where a series of N-S faults dominate, while the fault plane solutions of the earthquakes are attributed to east-west normal faults. HAN and JIANG (2004) 
based on the small slip degree suggested that the first Batang earthquake occurred on a blind fault. The fault segment associated with the second Batang earthquake is inside a bright zone (Figure 40 ), and is probably triggered by the former shock of the sequence. The calculation in the stress evolutionary model extends up to the present and the current stress field is compared with the smaller magnitude seismicity, which seems to be located in stress enhanced areas (Figure 4p).

\subsection{Central Sichuan-Yunnan region}

The stress evolution in the central part of our study region since the beginning of 20th century is illustrated in Figure 5. The first event occurred in 1925 and the coseismic stress change is shown in Figure 5a. It creates bright zones along the northeastern continuation of the Red River fault. In Figure 5b the state of stress before the 1952 earthquake in Anninghe fault is displayed. A broad area of positive stress change has been created that is attributed to the 27 years (1925 1952) of tectonic loading. The occurrence of the 1955 main shock is in accordance with the stress evolutionary model (Figure 5c), although its epicentre is located far from the previous event and possible triggering cannot be substantiated. The stress bright zones where the next main events occurred (1966 event (Figure 5d), 1974 Panxi rift (Figure 5e), 1976 event (Figure 5f ), 1995 event (Figure 5g), and 1996 event (Figure 5h)) are mainly due to the tectonic loading. The characteristic feature of this area is that strong earthquakes occur in long distances and are randomly distributed in contrast with the other two sub regions where seismicity occurs along the known fault zones

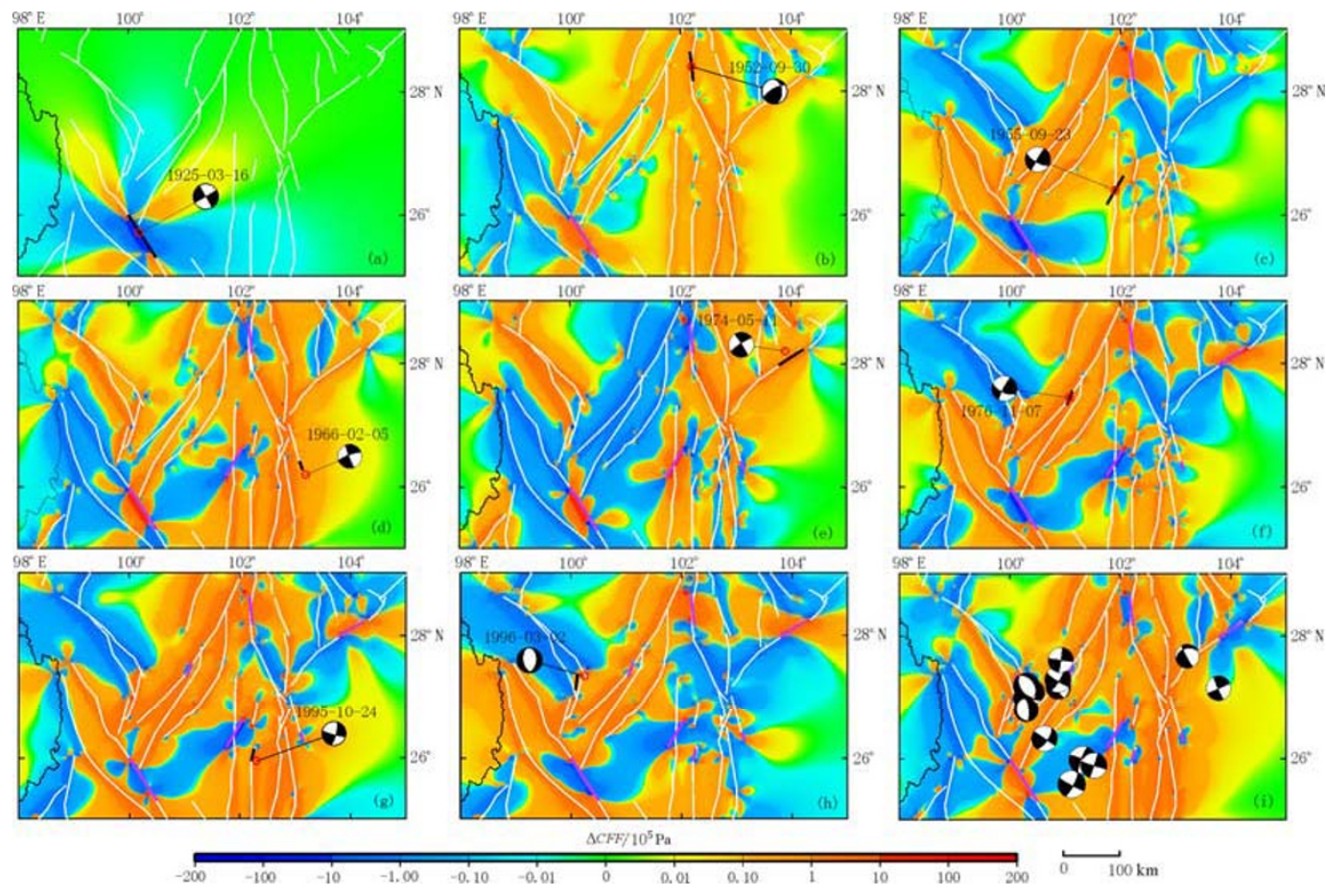

Figure 5 Stress evolution in central region regarding South Sichuan and North Yunnan province Coulomb stress changes are calculated at a depth of $8 \mathrm{~km}$. (a) Coseismic Coulomb Stress Changes associating to 1925 event; (b) Stress state just before 1952 event along Anninghe fault; (c) Stress field before the strong 1955 event; (d) Computed stress just before 1966 event; (e) Stress changes until the occurrence of 1974 event; (f) Stress field just before 1976 event; (g) Stress field before the strong 1995 event; (h) Stress model before the devastating 1996 Lijiang earthquake; (i) Stress field after 1996 in the central area accompanied with strong events that followed 
and close in time on adjacent fault segments. The majority of earthquakes with $M<6.5$ after 1996 seem to occur in stress enhanced areas (Figure $5 \mathrm{i}$ ).

\subsection{Southern Yunnan region}

The first strong earthquake that struck the southern part of our study area occurred in 1913 in an active structure that ruptured twice in the 20th century. The coseismic stress change of this event is shown in Figure 6. The stress evolution just before the occurrence of the 1941 event is shown in Figure 6b. The 1941 event is located quite far to be triggered by the previous occurrence, while it is the positive stress changes along the southern adjacent fault segment where the next main shock occurred in 1950 (Figure 6c). Triggering is also evidenced by the 1913 main shock to the 1970 one, which is associated with a fault segment adjacent to that of the 1913 main shock (Figure 6d), through stress transfer between the adjacent fault segments. The 1971 event occurred in a bright zone when the stress filed is calculated according to its faulting type (Figure 6e).

The 1976 Longling sequence started with the first event being inside a stress enhanced area due only to the tectonic loading since it is located far enough from previous strong events being hardly triggered by them (Figure 6f), but they evidently triggered the second event of the sequence that took place in an adjacent fault segment (Figure 6g). Eight years after the 1971 main shock a second one struck the same area (Figure 6h), being located in an area between positive and negative $\triangle C F F$ values. The 1983 earthquake associated with the Dien Bien Phu fault in Northern Vietnam is due solely to the tectonic loading since it is quite far from the previous events and therefore triggering cannot be inferred (Figure 6i).

The 1988 Lancang-Gengma sequence started with the activation of a fault segment adjacent to the one associated with the 1941 main shock. The first Lancang 1988 event was probably triggered by stress transfer due to the coseismic slip of the event (Figure 6j). The second 6 November 1988 Gengma main shock of this sequence is evidently triggered by the previous one (Figure 6k), as both are associated with the adjacent fault segment of the same strike. The occurrence of the last 1995 strong event in this part of our study area occurred in a stress enhanced area in accordance with the stress evolutionary model (Figure 61). Earthquakes with magnitude $M \leq 6.5$ after 1995 have occurred in bright regions as well (Figure 6m).

\section{Discussion and conclusions}

In order to evaluate future seismic hazard, we applied a stress evolutionary model for the Sichuan and Yunnan region of China. The evolution starts at the beginning of the 20th century and is accomplished in this study by calculating the static stress change due to coseismic slip of the strong events and long term tectonic loading on major regional faults. The stress evolution of the stress field was calculated for the time intervals 1904 2007, 1925 2007, 1913 2007 for the northern, central, and southern region, respectively. Initial stress values just before the 1904, 1925 and 1913 event are assigned to be zero everywhere. The fact that the region has been divided into three sub-regions has no effect on the calculation of stress change since the events are located in large distances. It has been shown that there is no important impact. The time advance of the shocks is less important in distant places such as the central area. The study area includes first order tectonic complexities have been taken into account as the regional fault network, while minor active faults are not included. Thus, for a more detailed survey the results are presented separately for each one of the three sub areas. 

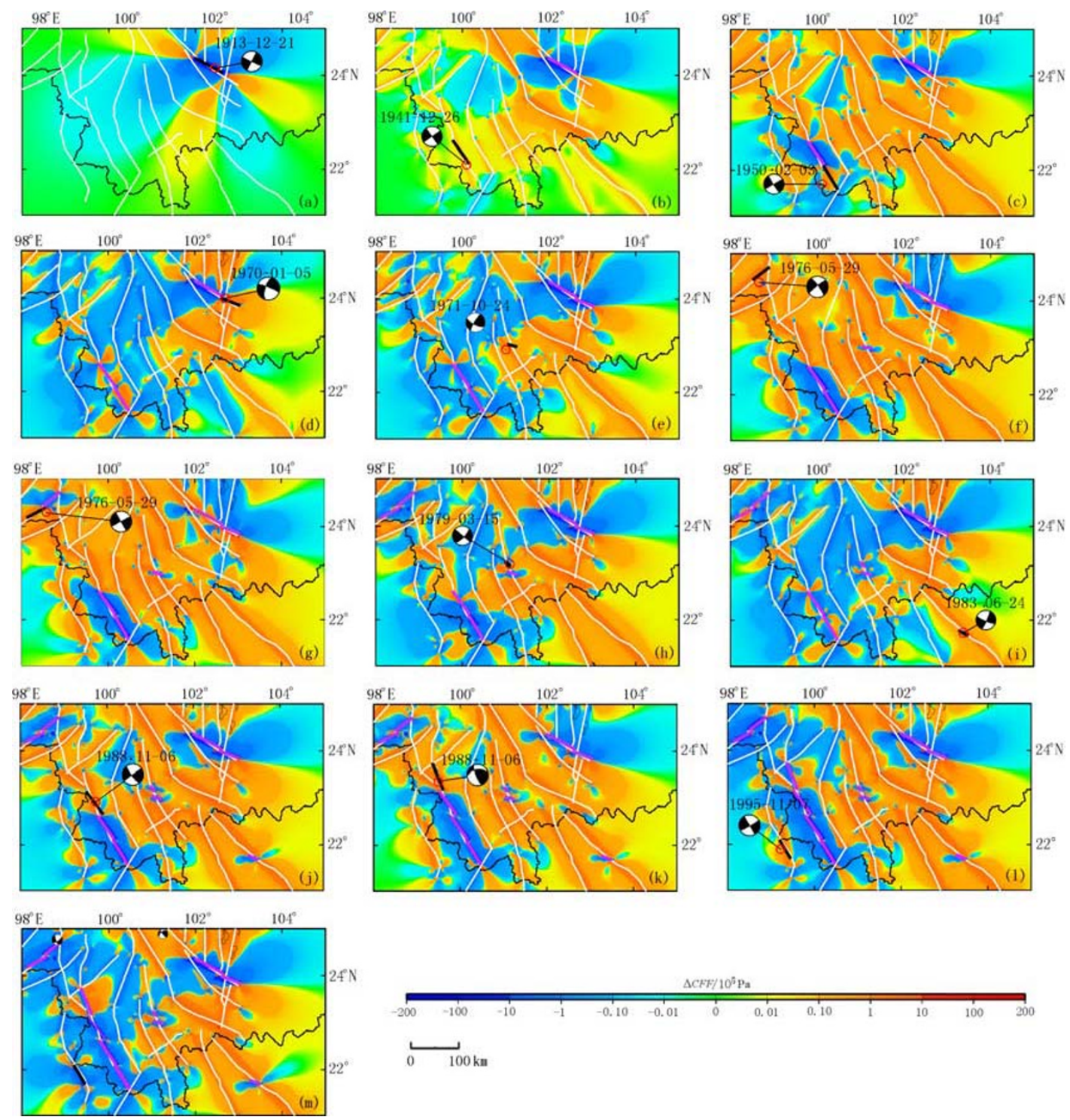

Figure 6 Stress evolution in southern region regarding South Yunnan province at its borders with Myanmar and Vietnam

Coulomb stress changes are calculated for the depth of $8 \mathrm{~km}$. (a) Coseismic Coulomb Stress Changes associating to 1913 event; (b) Stress state just before 1941 shock at Lancang-Gengma fault zone; (c) Stress field before the strong 1950 event along the same fault zone; (d) Computed stress just before 1970 Tonghai event; (e) Stress changes until the occurrence of 1971 event; (f) Stress field just before 1976 sequence; (g) Stress field before the second main shock; (h) Stress model before the devastating 1979 earthquake; (i) Stress state just before 1983 event; (j) Stress field before the 1988 Lung-Ling sequence. The epicentre of the first main shock is displayed; (k) Stress field after the first main shock; (1) Stress field after the second main shock of the sequence; (m) Stress variations after the last strong event of 1995. Latter strong events with magnitude $M>6.0$ are also presented

Stress transfer among adjacent faults or fault segments, or conjugate faults is confirmed to dominate in this area. In most of the cases triggering is evidenced and many events are located in bright zones where static stress changes have relatively high positive values. Although fault 
Table 5 Rupture models for earthquakes with $M \geq 6.5$ that occurred in the central part (southern Sichuan-northern Yunnan Province) of the study area from 1925 to 1996 and are included in the evolutionary model

\begin{tabular}{|c|c|c|c|c|c|c|c|c|c|c|c|c|c|}
\hline \multirow{2}{*}{$\begin{array}{c}\text { Date } \\
\text { a-mo-d }\end{array}$} & \multirow{2}{*}{ Location } & \multicolumn{2}{|c|}{ Epicenter } & \multicolumn{2}{|c|}{$\begin{array}{l}\text { Magni- } \\
\text { tude }\end{array}$} & \multicolumn{3}{|c|}{ Fault plane solution } & \multirow{2}{*}{$L / \mathrm{km}$} & \multirow{2}{*}{$U / \mathrm{m}$} & \multirow{2}{*}{$S S / \mathrm{m}$} & \multirow{2}{*}{$D S / \mathrm{m}$} & \multirow{2}{*}{ Ref } \\
\hline & & $\varphi_{\mathrm{N}} /^{\circ}$ & $\lambda_{\mathrm{E}} /^{\circ}$ & $M_{\mathrm{S}}$ & $M_{\mathrm{W}}$ & Strike/ ${ }^{\circ}$ & $\mathrm{Dip} /{ }^{\circ}$ & Rake $^{\circ}$ & & & & & \\
\hline $1925-03-16$ & Red River & 25.70 & 100.20 & 6.8 & 7.0 & 150 & 90 & 180 & 68 & 1.48 & -1.48 & 0 & 1 , Eq. $5 \sim 6$ \\
\hline 1952-09-30 & Anninghe & 28.40 & 102.20 & 6.8 & - & 354 & 40 & 30 & 52 & 1.08 & +0.93 & -0.54 & 2 , Eq. $5 \sim 6$ \\
\hline 1955-04-14 & Xiaojiang faults & 30.00 & 101.90 & 6.8 & 7.5 & 210 & 87 & 20 & 59 & 1.26 & +1.18 & -0.43 & 3, Eq. $5 \sim 6$ \\
\hline 1966-02-05 & Xiaojiang faults & 26.20 & 103.20 & 6.5 & 6.9 & 159 & 85 & -11 & 17 & 0.31 & +0.3 & +0.06 & 3, Eq. $5 \sim 6$ \\
\hline 1974-05-11 & Huayinshan & 28.20 & 103.90 & 7.1 & 6.8 & 237 & 81 & 176 & 52 & 1.08 & +1.06 & -1.19 & 3, Eq. $5 \sim 6$ \\
\hline 1976-11-07 & Qinhe & 27.45 & 101.08 & 6.7 & 6.3 & 19 & 66 & -6 & 26 & 0.47 & +0.42 & -0.21 & 3, Eq. $5 \sim 6$ \\
\hline 1995-10-24 & Xiaojiang faults & 25.95 & 102.30 & 6.5 & 6.2 & 13 & 75 & -9 & 23 & 0.23 & +0.23 & +0.04 & 3, Eq. $5 \sim 6$ \\
\hline 1996-02-03 & Lijiang & 27.34 & 100.25 & 7.0 & 6.6 & 6 & 44 & -78 & 28 & 0.35 & 0.07 & 0.34 & 4,5, Eq. 7 \\
\hline
\end{tabular}

Table 6 Rupture models for earthquakes with $M \geq 6.5$ that occurred in the southern part (southern Yunnan Province) of the study area from 1913 to 1988 and included in the evolutionary model

\begin{tabular}{|c|c|c|c|c|c|c|c|c|c|c|c|c|c|}
\hline \multirow{2}{*}{$\begin{array}{c}\text { Date } \\
\text { a-mo-d }\end{array}$} & \multirow{2}{*}{ Location } & \multicolumn{2}{|c|}{ Epicenter } & \multicolumn{2}{|c|}{ Magnitude } & \multicolumn{3}{|c|}{ Fault plane solution } & \multirow{2}{*}{$L / \mathrm{km}$} & \multirow{2}{*}{$U / \mathrm{m}$} & \multirow{2}{*}{$S S / \mathrm{m}$} & \multirow{2}{*}{$D S / \mathrm{m}$} & \multirow{2}{*}{ Ref. } \\
\hline & & $\varphi_{\mathrm{N}}{ }^{\circ}$ & $\lambda_{\mathrm{E}} /^{\circ}$ & $M_{\mathrm{S}}$ & $M_{\mathrm{W}}$ & Strike & Dip & Rake & & & & & \\
\hline $1913-12-21$ & Qujiang & 24.15 & 102.45 & 7.0 & 7.2 & 116 & 87 & 180 & 89 & 2.02 & -2.02 & 0 & 1, Eq.5-6 \\
\hline $1941-12-26$ & Lancang & 22.10 & 100.10 & 7.0 & 7.0 & 145 & 90 & 180 & 68 & 1.48 & -1.48 & -0.13 & 1, Eq.5-6 \\
\hline $1950-02-03$ & Lancang & 21.70 & 100.10 & 7.0 & 7.0 & 149 & 85 & 180 & 68 & 1.48 & -1.48 & 0 & 1, Eq.5-6 \\
\hline 1970-01-05 & Qujiang & 24.00 & 102.70 & 7.8 & - & 291 & 80 & $\begin{array}{r}-15 \\
7\end{array}$ & 102 & 2.37 & -2.18 & +0.93 & 2, Eq. 6 \\
\hline $1971-04-28$ & Lancang & 22.90 & 101.00 & 6.7 & 6.3 & 117 & 70 & 170 & 26 & 0.49 & +0.48 & -0.08 & 1, Eq. 6 \\
\hline $1976-05-29$ & Ruili & 24.50 & 99.00 & 7.3 & 6.7 & 232 & 82 & -10 & 50 & 0.92 & +0.90 & +0.16 & 1, Eq. $5-6$ \\
\hline $1976-05-29$ & Ruili & 24.45 & 98.86 & 7.4 & 6.7 & 242 & 88 & 0 & 50 & 0.92 & +0.92 & 0 & 1, Eq. $5-6$ \\
\hline 1979-03-15 & Pu'er & 23.20 & 101.10 & 6.8 & 6.0 & 312 & 86 & 163 & 17.5 & 0.31 & -0.29 & -0.09 & 1, Eq.5-6 \\
\hline 1983-06-24 & Dien Bien Phu & 21.72 & 103.38 & 6.8 & 6.3 & 114 & 80 & $\begin{array}{r}-17 \\
2\end{array}$ & 26 & 0.5 & -0.49 & +0.44 & 1, Eq.5-6 \\
\hline 1988-11-06 & Lancang & 22.92 & 99.75 & 7.4 & 7.0 & 144 & 79 & 179 & 68 & 1.48 & -1.48 & -0.03 & 3,4 , Eq.5-6 \\
\hline 1988-11-06 & Lancang & 23.37 & 99.50 & 7.2 & 7.0 & 158 & 77 & 136 & 68 & 1.48 & -1.06 & -1.03 & 5, Eq.5-6 \\
\hline 1995-07-11 & Myanmar & 21.89 & 99.22 & - & 6.8 & 330 & 89 & 175 & 52 & 1.08 & -1.07 & +0.09 & 1, Eq. $5-6$ \\
\hline
\end{tabular}

Note: 1: Yang et al (2005), 2: Zhou et al (1983a), 3: Chen and Wu (1989), 4: Mozzafari et al (1998), 5: Jiang (1993). $L$ stands for fault length, and $U, S S, D S$ for displacement, slip along strike and slip along dip, respectively.

surfaces are irregular and ruptures are more complicated, meaning that slip is not uniform but varies along its segments, it is believed that the approximate models are sufficient for identifying the areas of stress change when they are computed for distances far from the causative fault. A subsequent event can be triggered on the faults having proper orientation and being close to failure even if the stress change is only a few bars. Stress increment does not declare subsequent epicenter location but correspond to the segment sufficient to fail because it has reached high stress level and is close to failure, in accordance with Coulomb failure criterion. However, there are cases where epicenters are found in stress shadows before reloading. This fact can be attributed to fault interaction that inhibits faults to complete an integral seismic cycle and they rupture before approaching the required maximum stress or different seismic cycles exist in a small area. Misfits in the stress computation are attributed to the complexity and the existence of minor faults in this multi-segmented crust. The accumulative result of possible post seismic effects, such as viscoelastic relaxation beneath the brittle part of the crust and transient postseismic slip below the rupture zone are not incorporated in the evolutionary model. Stress diffusion in each case needs further 
study since there is a wide variation in the post seismic behavior of rupture. Thus, it is suggested (Jaumé, 1994) that the postseismic slip when exists, will reinforce both regional stress and stress change caused by coseismic slip. These effects, along with differences in non-elastic changes and rate-state friction are not included, since they need to be addressed in further study.

The results were extrapolated to 2007 so as to determine the areas with current enhanced stress change where an earthquake is likely to occur, assuming that no other strong earthquake has occurred until now. The final patterns are illustrated in Figure 7 and changes are calculated for the strike, dip and rake of the representative faulting type of each subarea. The model results indicate that some faults are encouraged to rupture whereas in many areas there is a fault relaxation and a quiescence seismic period follows. The results derived from the evolutionary model coincide with the ones of Papadimitriou et al (2004) who suggested that stress transfer is a driving mechanism in the whole area and seismic activation is expected to be started in segments of bright zones. A
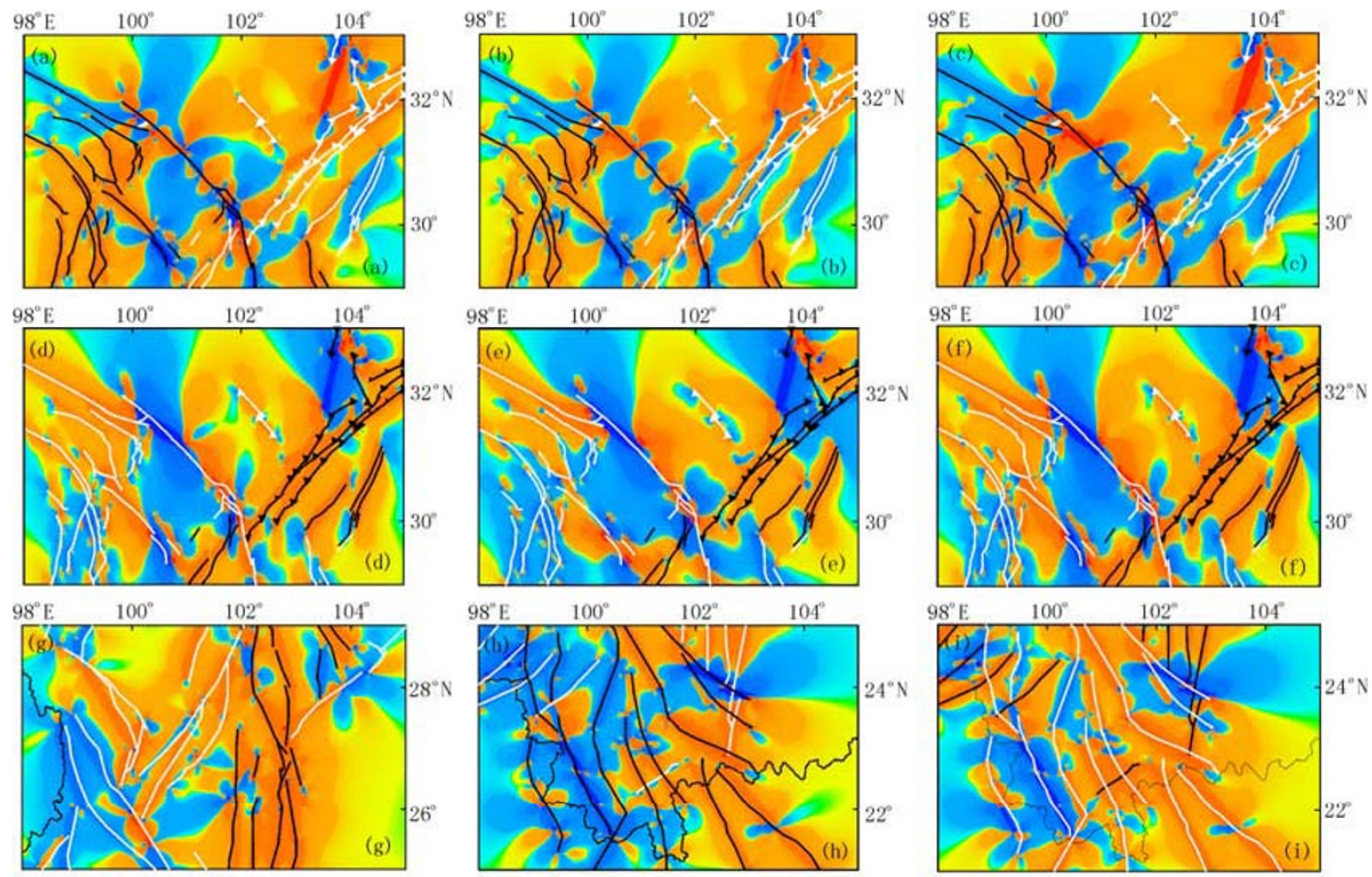

$\triangle C F F / 10^{5} \mathrm{~Pa}$

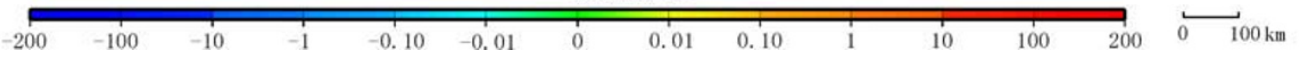

Figure 7 Coulomb stress evolution computed extrapolated for 2007 for the northern the central and the southern region at the depth of $8.0 \mathrm{~km}$

The stress model has been computed for different fault types, coloured black, with a mean fault plane solution, for a different value of the effective coefficient of friction, $\mu^{\prime}$; (a) Calculations for the northern Region for a fault with mean fault plane solution $160^{\circ} / 80^{\circ} /-10^{\circ}$ for $\mu^{\prime}=0.2$; (b) Calculations for the northern region for a fault with mean fault plane solution $160^{\circ} / 80^{\circ} /-10^{\circ}$ for $\mu^{\prime}=0.4$; (c) Calculations for the northern region for a fault with mean fault plane solution $60^{\circ} / 80^{\circ} /-10^{\circ}$ for $\mu^{\prime}=0.6$; (d) Calculations for the northern region for a fault with mean fault plane solution $240^{\circ} / 50^{\circ} /-170^{\circ}$ for $\mu^{\prime}=0.2$; (e) Calculations for the northern region for a fault with mean fault plane solution $240^{\circ} / 50^{\circ} /-170^{\circ}$ for $\mu^{\prime}=0.4$; (f) Calculations for the northern region for a fault with mean fault plane solution $240^{\circ} / 50^{\circ} /-170^{\circ}$ for $\mu^{\prime}=0.6$; (g) Coulomb stress evolution computed, extrapolated for 2007 for the central region at the depth of $8.0 \mathrm{~km}$, for a fault with $350^{\circ} / 80^{\circ} / 30^{\circ}$ for $\mu^{\prime}=0.4$; (h) Coulomb stress evolution computed, extrapolated for 2007 for the southern region for a fault with $130^{\circ} / 85^{\circ} / 170^{\circ}$ for $\mu^{\prime}=0.4$; (i) Calculations for the southern region for a fault with $230^{\circ} / 85^{\circ} / 5^{\circ}$ for $\mu^{\prime}=0.4$ 
similar study of WAN et al (2007), whose evolutionary model includes some common studied earthquakes (the 1973, 1955, 1933, 1976a, 1976b earthquake), proves that strong earthquakes $(M \geq 7.0)$ are highly triggered by their previous ones.

Alternative values of the apparent friction coefficient are testified in our calculations. In particular, lower $\left(\mu^{\prime}=0.2\right)$ and higher values $\left(\mu^{\prime}=0.6\right)$ were used. The resulted computation of the stress evolution shows unimportant difference in stress pattern. Low sensitivity has been noticed but not to such a degree resulting to the alteration of the sign of the calculated stress field. Parsons et al (2006) conducted a similar test in the adjacent region of Himalaya and reached the same results. Based on the above discussion, the value of the apparent coefficient of friction selected and used in the present study $\left(\mu^{\prime}=0.4\right)$ is suitable for the performed calculations (Figure 7).

A feature characterising long fault zones is that they are found segmented and distinct parts of faults rupture each time until they complete a seismic cycle. It is evidenced in the present study that strong earthquakes in a long fault zone undoubtfully encourage a second event along strike. Characteristic examples are demonstrated in the case of Xianshuihe fault zones in northern Sichuan and Lancang-Gengma fault zone in southern Yunnan, where almost all the segments of the fault have ruptured in the last century. According to YI et al (2000) the Xianshuihe-Anninghe-Zemuhe left lateral strike slip fault possesses the ability for mechanical interaction between adjacent fault segments and this is confirmed by stress bright zones revealed in the model. In Figure 7a it is noticed that the southern segment of Xianshuihe remains unruptured, and it lays inside stress enhanced region, therefore, a future rupture is anticipated. These results are in accordance with the calculations made by WEN et al (2002) who assessed a high probability for the Minjiang segment to fail. For the case of Lancang-Gengma rupture zone, we notice that seismic excitation begins with the 1950 main shock, which ruptures the southern part of the zone and occurs in a highly enhanced segment. After 38 years the Lancang-Gengma doublet broke the whole stress increased northern part of the zone. In the 2007 calculation no seismic hazard is posed for this area. Qujiang fault also seems to be triggered by stress transfer along strike since the strong Tonghai event has possibly been triggered by the previous event in 1913 on the same fault. Clustering is also confirmed by Songpan triplet in Minjiang fault zone.

Most earthquakes concentrate in the places around fault tips or on the sites where fault changes its strike since there is a high stress increase. Coulomb stress changes certainly influence the location and timing of the following earthquakes and can serve as a fundamental tool in seismic hazard assessment since there is a correspondence between positive changes and earthquake occurrence.

Acknowledgements The stress tensors were calculated using a program written by Deng and Sykes (1997) based on the DIS3D code of S. Dunbar, which later improved (Erikson, 1986) and the expressions of G. Converse. The GMT system (Wessel and Smith, 1998) was used to plot the figures. The creative revision and the editorial assistance of Professor LIU Xin-mei (Institute of Geophysics, China Earthquake Administration) are kindly acknowledged. Gratitude is also extended to Prof. WANG Xiao-qing (Institute of Earthquake Science, China Earthquake Administration).

\section{References}

Allen C, Gillespie A, Han Y, Sieh K, Zhang B, Zhu C. 1984. Red River and associated faults, Yunnan Province, China: Quaternary geology, slip rates, and seismic hazard [J]. Geol Soc Am Bull, 95: 686-700. 
Allen C, Luo Z, Qian H, et al. 1991. Field study of a highly active fault zone: The Xianshuihe fault of Southwestern China [J]. Geol Soc Am Bull, 103: 1 178-1 199.

Armijo R, Tapponnier P, Mercier J L, et al. 1986. Quaternary extension in southern Tibet: Field observations and tectonic implications [J]. J Geophys Res, 91: 13 803-13 872.

Chen Y T and Wu F T. 1989. Langcang-Gengma earthquake: A preliminary report on the November 6, 1988 event and its aftershocks [J]. Eos Trans Amer Geophys Union, 12: 1527-1540.

Chen Z, Burchfiel C, Liu Y, et al. 2000. Global positioning system measurements from eastern Tibet and their implications for India/Eurasia intercontinental deformation [J]. J Geophys Res, 105: 16215-16227.

Deng J and Sykes L. 1997. Evolution of the stress field in southern California and triggering of moderate-size earthquakes: A 200-year perspective [J]. J Geophys Res, 102: $9859-9886$.

Engdahl E R, Van Der Hilst R D, Buland R P. 1998. Global teleseismic earthquake relocation with improved travel times and procedures for depth determination [J]. Bull Seism Soc Amer, 88: 722-743.

Erikson L. 1986. User's manual for DIS3D: A three-dimensional dislocation program with applications to faulting in the Earth. Masters Thesis, Stanford Univ., Stanford, Calif, 167.

Gao Y, Wu Z, Liu Z, et al. 2000. Seismic source characteristics of nine strong earthquakes from 1988 to 1990 and earthquake activity since 1970 in the Sichuan-Qinghai-Xizang (Tibet) Zone in China [J]. Pure Appl Geophys, 157: 1423-1 443.

HAN Wei-bin and JIANG Guo-fang. 2004. Study on distribution characteristics of strong earthquakes in Sichuan-Yunnan area and their geological tectonic background [J]. Acta Seismologica Sinica, 17(2): 230-243.

Harris R and Simpson R. 1993. In the shadow of 1857: An evaluation of the static stress changes generated by the M8 Ft. Tejon, California, earthquake [J]. Eos, Trans Amer Geophys Union, 74 (43): 427.

Harris R and Simpson R. 1996. In the shadow of 1857: The effect of the great Ft Tejon earthquake on subsequent earthquakes in Southern California [J]. Geophys Res Lett, 23: 229-232.

Holt W, Chamot-Rooke N, Le Pichon X, et al. 2000. Velocity field in Asia inferred from Quaternary fault slip rates and Global Positioning System [J]. J Geophys Res, 105: 19 185-19209.

Holt W, Ni J, Wallace T, et al. 1991. The active tectonics of the Eastern Himalayan Syntaxis and surrounding regions [J]. J Geophys Res, 96: $14595-14632$.

Jaumé S C. 1994. Earthquakes in an evolving stress/strain field [D][PhD Dissertation]. New York: Columbia University: 261.

Jiang K. 1993. The 1988 Lancang-Gengma Earthquakes (M=7.6, 7.2) in Yunnan, China [M]. Kunming: Yunnan University Press, 387 (in Chinese).

Jones L, Han W, Hauksson E, et al. 1984. Focal mechanisms and aftershock locations of the Songpan earthquakes of August 1976 in Sichuan, China [J]. J Geophys Res, 89: 7 697-7 707.

King G, Stein R, Lin J. 1994. Static stress changes and the triggering of earthquakes [J]. Bull Seism Soc Amer, 84: $935-953$.

Kirby E, Whipple K, Burchfiel BC, et al. 2000. Neotectonics of the Min Shan, China: Implications for mechanisms driving Quaternary deformation along the eastern margin of the Tibetan Plateau [J]. Geol Soc Am Bull, 112: 375-393.

Leloup P, Lacassin R, Tapponier P, et al. 1995. The Ailao Shan-Red River shear zone (Yunnan, China), Tertiary transform boundary of Indochina [J]. Tectonophysics, 251: 3-84.

Molnar P and Deng, Q. 1984. Faulting associated with large earthquakes and the average rate of deformation in central and eastern Asia [J]. J Geophys Res, 89: 6203-6227.

Molnar P and Tapponnier P. 1977. Relation of the tectonics of eastern China to the India-Eurasia collision: Application of slip-line field theory to large scale continental tectonics [J]. Geology, 5: 212-216.

Mozaffari P, Wu Z L, Chen Y T. 1998. Rupture process of November 6, 1988, Lancang-Gengma, Yunnan, China, earthquake of $M_{\mathrm{S}}=7.6$ using empirical Green's function deconvolution method [J]. Acta Seismologica. Sinica, 11: 1-12.

Nalbant S, McCloskey J, Steacy S, et al. 2002. Stress accumulation and increased seismic risk in eastern Turkey [J]. Earth Planet Sci Lett, 195: 291-298.

Nur A and Mavko G. 1974. Postseismic viscoelastic rebound [J]. Science, 183: 204-206.

Okada Y. 1992. Internal deformation due to shear and tensile faults in a half space [J]. Bull Seism Soc Amer, 82: 1 018-1 040.

Papadimitriou E, Wen X, Karakostas V, et al. 2004. Earthquake triggering along the Xianshuihe fault zone of western Sichuan, China [J]. Pure Appl Geophys, 161: 1 683-1 707.

Papazachos B, Scordilis E, Panagiotopoulos D, et al. 2004. Global relations between seismic fault parameters and moment magnitude of earthquakes [J]. Bull Geol Soc Greece, 36: $1482-1489$.

Parsons T, Roberts S, Yuji Y, et al. 2006. Static stress change from the 8 October, $2005 \mathrm{M}=$ Kashmir earthquake [J]. Geophys Res Lett, 33: L06304, doi:10.1029/2005GL025429.

Parsons T, Stein R, Reasenberg A. 1999. Stress sensitivity of fault seismicity: A comparison between limited-offset oblique and major strike-slip faults [J]. J Geophys Res, 104: 20 183-20 202.

Peltzer G and Saucier F. 1996. Present-day kinematics of Asia derived from geologic fault rates [J]. J Geophys Res, 101: $27943-27956$.

Qin C, Papazachos C, Papadimitriou E. 2002. Velocity field for crustal deformation in China derived from seismic moment tensor summation of earthquakes [J]. Tectonophysics, 359: 29-46.

Reasenberg A and Simpson R. 1992. Response of regional seismicity to the static stress change produced by the Loma Prieta earthquake [J]. Science, 255: $1687-1690$.

Replumaz A, Lacassin R, Tapponier P, et al. 2001. Large River offsets and Plio-Quaternary dextral slip rate on the Red River Fault (Yunnan, China) [J]. J Geophys Res, 106: 819-836.

Royden L, Burchfiel C, King R, et al. 1997. Surface deformation and lower crustal flow in eastern Tibet [J]. Science, 276: 788-790.

Scholz C. 2002. The mechanics of earthquakes and faulting [J]. Cambridge: Cambridge University Press: 439. 
Socquet A and Pubbelier M. 2005. Cenozoic deformation in western Yunnan (China-Myanmar border) [J]. J Asian Earth Sci, 24: 495-515. Stein R. 1999. The role of stress transfer in earthquake occurrence [J]. Nature, 402: 605-609.

Steketee J. 1958. On Voltera's dislocations in a semi-infinite elastic medium [J]. Can J Phys, 36: 192-205.

Tang R, Huang Z, Qian H, et al. 1984. On the recent tectonic activity and earthquake of Xianshuihe fault zone [C]//A Collection of Papers of International Symposium of on Continental Seismicity and Earthquake Prediction. Beijing: Seismological Press: 347-363.

Toda S, Stein R, Reasenberg A, et al. 1998. Stress transferred by the $1995 M_{\mathrm{W}}=6.9$ Kobe, Japan, shock: Effect on aftershocks and future earthquake probabilities [J]. J Geophys Res, 103: 24 543-24 565.

WAN Yong-ge, SHEN Zheng-kang, ZENG Yue-hua, et al. 2007. Evolution of cumulative Coulomb failure stress in northeastern Qinghai-Xizang (Tibetan) Plateau and its effect on large earthquake occurrence [J]. Acta Seismologica Sinica, 20(2): 117-132.

Wang E and Burchfiel C. 2000. Late Cenozoic to Holocene deformation in southwestern Sichuan and adjacent Yunnan, China and its role in formation of the southeastern part of the Tibetan Plateau [J]. J Geophys Res, 112: 413- 423.

Wang Y. 1996. Principal features of the active tectonics in Qinghai-Xizard plateau [J]. J Earth Pred Res, 5: 348-362.

WEN X, Yi G, ZHANG P, et al. 2002. A preliminary evaluation of time-dependent seismic hazard for the eastern-boundary fault zone of Sichuan-Yunnan Block, China [C]//Teruyuki K and Zheng S ed. Proceedings of the First China-Japan Workshop on Earthquake Disaster Mitigation. Japan: Earthquake Research Institute: 141-154.

Wen X. 2000. Character of rupture segmentation of the Xianshuihe-Anninghe-Zemuhe fault-zone, western Sichuan [J]. Seismology and Geology, 22: 239-249 (in Chinese).

Wessel P and Smith W H F. 1998. New, improved version of the Generic Mapping Tools Released, EOS Trans. AGU 79, 579. (net being cited)

$\mathrm{Xu}$ X, Wen X, Zheng R, et al. 2003. Pattern of latest tectonic motion and its dynamics for active blocks in Sichuan-Yunnan region, China [J]. Science in China (Series D), 33(Suppl.): 151-162.

Yang Z, Waldhauser F, Chen Y, et al. 2005. Double difference relocation of earthquakes in central-western China [J]. J Seismology, 9: 241-264.

YI Gui-xi and WEN Xue-ze. 2000. Earthquake recurrence on whole active fault zones and its relation to that on individual fault segments [J]. Acta Seismologica Sinica, 13: 563-574.

YI Gui-xi, WEN Xue-ze, FAN Jun, et al. 2004. Assessing current faulting behaviors and seismic risk of the Anninghe-Zemuhe fault zone from seismicity parameters [J]. Acta Seismologica Sinica, 17(3): 322-333.

Zhao S, Dingbo C, Xian L, et al. 1999. The $M_{\mathrm{L}}=7.0$ Lijiang earthquake, Yunnan, China: An anticipated event [J]. J Geodynamics, 16: 529-546.

Zhou H, Allen C, Kanamori H. 1983a. Rupture complexity of the 1970 Tonghai and 1973 Luhuo earthquakes, China, from P wave inversion, and relationship to surface faulting [J]. Bull Seism Soc Amer, 73: 1585-1 597.

Zhou H, Liu H, Kanamori H. 1983b. Source processes of large earthquakes along the Xianshuihe fault in southwestern China [J]. Bull Seism Soc Amer, 73: 537-551. 